\title{
Liquidity of Corporate Bonds
}

\author{
Jack Bao, Jun Pan and Jiang Wang*
}

This draft: July 9, 2008

\begin{abstract}
This paper examines the liquidity of corporate bonds and its asset-pricing implications using a novel measure of illiquidity based on the magnitude of transitory price movements. Using transaction-level data for a broad cross-section of corporate bonds from 2003 through 2007, we find the illiquidity in corporate bonds to be significant, substantially greater than what can be explained by bid-ask bounce, and closely linked to liquidity-related bond characteristics. More importantly, we find a strong commonality in the time variation of bond illiquidity, which rises sharply during market crises and reaches an all-time high during the recent sub-prime mortgage crisis. Monthly changes in this aggregate bond illiquidity are strongly related to changes in the CBOE VIX Index and lagged stock market returns. Examining its relation with bond pricing, we find that our measure of illiquidity explains the cross-sectional variation in average bond yield spreads with large economic significance.
\end{abstract}

*Bao is from MIT Sloan School of Management (jackbao@mit.edu); Pan is from MIT Sloan School of Management and NBER (junpan@mit.edu); and Wang is from MIT Sloan School of Management, CCFR and NBER (wangj@mit.edu). The authors thank Andrew Lo, Ananth Madhavan and participants at the 2008 JOIM Spring Conference for helpful comments. Support from the outreach program of J.P. Morgan is gratefully acknowledged. 


\section{Introduction}

The liquidity of the corporate bond market has been of interest for researchers, practitioners and policy makers. Many studies have attributed deviations in corporate bond prices from their "theoretical values" to the influence of illiquidity in the market. ${ }^{1}$ Yet, our understanding of how to quantify illiquidity remains limited. Without a credible measure of illiquidity, it is difficult to have a direct and serious examination of the asset-pricing influence of illiquidity and its implications on market efficiency.

Several measures of illiquidity have been considered in the literature for corporate bonds. A simple measure is the bid-ask spread, which is analyzed in detail by Edwards, Harris, and Piwowar (2007). ${ }^{2}$ Although the bid-ask spread is a direct and potentially important indicator of illiquidity, it does not fully capture many important aspects of liquidity such as market depth and resilience. Alternatively, relying on theoretical pricing models to gauge the impact of illiquidity allows for direct estimation of its influence on prices, but suffers from potential mis-specifications of the pricing model.

In this paper, we rely on a salient feature of illiquidity to measure its significance. It has been well recognized that the lack of liquidity in an asset gives rise to transitory components in its prices (see, e.g., Grossman and Miller (1988) and Huang and Wang (2007)). The magnitude of such transitory price movements reflects the degree of illiquidity in the market. Since transitory price movements lead to negatively serially correlated price changes, the negative of the autocovariance in price changes, which we denote by $\gamma$, provides a simple, yet robust measure of illiquidity. In the simplest case when the transitory price movements arise purely from bid-ask bounce, as considered by Roll (1984), $2 \sqrt{\gamma}$ equals the bid-ask spread. But in more general cases, $\gamma$ captures the broader impact of illiquidity on prices, above and beyond the effect of bid-ask spread. Moreover, it does so without relying on specific bond pricing models.

Indeed, our results show that the lack of liquidity in the corporate bond market is substantial, significantly more severe than what can be explained by bid-ask bounce, and closely related to bond characteristics that are known to be linked to liquidity. More importantly,

\footnotetext{
${ }^{1}$ For example, Huang and Huang (2003) find that yield spreads for corporate bonds are too high to be explained by credit risk and question the economic content of the unexplained portion of yield spreads (see also Colin-Dufresne, Goldstein, and Martin (2001) and Longstaff, Mithal, and Neis (2005)). Bao and Pan (2008) document a significant amount of transitory excess volatility in corporate bond returns and attribute this excess volatility to the illiquidity of corporate bonds.
}

${ }^{2}$ See also Bessembinder, Maxwell, and Venkataraman (2006) and Goldstein, Hotchkiss, and Sirri (2007). 
taking advantage of this novel measure of illiquidity, we are able to analyze the time variation of the aggregate illiquidity in corporate bonds and its asset-pricing implications. The main results of our paper can be further detailed as follows.

First, we uncover a level of illiquidity in corporate bonds that is important both economically and statistically. Using TRACE, a transaction-level dataset, we estimate $\gamma$ for a broad cross-section of the most liquid corporate bonds in the U.S. market. Our results show that, using trade-by-trade data, the median estimate of $\gamma$ is 0.3598 , and the mean estimate is 0.5814 with a robust t-stat of 22.23; using daily data, the median $\gamma$ is 0.5533 , and the mean $\gamma$ is 0.9080 with a robust t-stat of 29.13. To judge the economic significance of such magnitudes, we can use the quoted bid-ask spreads to calculate a bid-ask implied $\gamma$. For the same sample of bonds and for the same sample period, we find that the median and mean $\gamma$ implied by the quoted bid-ask spreads are respectively 0.0302 and 0.0458 , which are tiny fractions of our estimated $\gamma$. An alternative comparison is to use the Roll's model to calculate the $\gamma$-implied bid-ask spread, which is $2 \sqrt{\gamma}$, and compare it with the quoted bid-ask spread. ${ }^{3}$ Using our median estimates of $\gamma$, the $\gamma$-implied bid-ask spread is $\$ 1.1996$ using trade-by-trade data and $\$ 1.4876$ using daily data, significantly larger than the median quoted bid-ask spread of $\$ 0.3160$ or the estimated bid-ask spread reported by Edwards, Harris, and Piwowar (2007) (see Section 5 for more details). Such comparisons clearly indicate that our illiquidity measure $\gamma$ captures the price impact of illiquidity above and beyond the effect of simple bid-ask bounce.

Second, we establish a robust connection between our illiquidity measure $\gamma$ and bond characteristics known to be relevant for liquidity. Regressing our illiquidity measure $\gamma$ on a spectrum of bond characteristics, we find a strong positive relation between $\gamma$ and bond age - a variable widely used in the fixed-income market as a proxy of illiquidity; and a strong negative relation between $\gamma$ and the size of the bond issuance - another variable potentially linked to bond liquidity. Moreover, we find that the measure of illiquidity captured by $\gamma$ is related to but goes beyond the information contained in the quoted bid-ask spreads. Specifically, adding the bid-ask implied $\gamma$ as an additional explanatory variable, we find that it has a positive cross-sectional relation with our $\gamma$ measure, but it does not alter the established cross-sectional relation between $\gamma$ and bond characteristics, including age and issuance size. We also take advantage of the trading variables included in our transaction-level data, and

\footnotetext{
${ }^{3}$ Roll's model assumes that directions of trades are serially independent. For a given bid-ask spread, positive serial correlation in trade directions, which could be the case when liquidity is lacking and traders break up their trades, tends to increase the implied bid-ask spreads for a given $\gamma$. This could potentially increase the magnitude of the $\gamma$ implied bid-ask spreads, further deepening its difference from the quoted bid-ask spreads.
} 
find that bonds with smaller average trade sizes typically have higher illiquidity measure $\gamma$. Controlling for other bond characteristics, we also find that bonds with credit default swaps traded on their issuers tend to have lower illiquidity measure $\gamma$.

Third, our illiquidity measure allows us to focus on the systematic component of bond illiquidity, examining its variation over time and its connection with broader financial markets. Over our sample period, there is a trend of decreasing $\gamma$, indicating an overall improvement of liquidity in the corporate bond market. Against this backdrop of an overall time trend, however, we find substantial monthly movements in the aggregate measure of illiquidity. In particular, the aggregate $\gamma$ rises sharply during market crises, including the periods that eventually lead to the downgrade of Ford and GM bonds to junk status, and reaches an all-time high during the sub-prime mortgage crisis that starts in August 2007.

Moreover, we find that the common illiquidity component uncovered by our analysis is closely connected with the changing conditions of broader financial markets. Specifically, regressing changes in aggregate $\gamma$ on changes in VIX, a variable typically known as the market "fear gauge," we find a positive and significant relation. Changes in aggregate $\gamma$ are also found to be positively related to changes in the aggregate default spread, and negatively related to the past-month performance of the aggregate stock and bond markets. When all these variables are used together, however, we find that that only changes in VIX and lagged aggregate stock returns remain significant in explaining the monthly changes in aggregate $\gamma$. In contrast, the default spread and lagged aggregate bond returns - two variables that are measured from the credit market and are expected to be more closely related to our $\gamma$ measure — fail to remain significant. Moreover, there is no significant relation between changes in our aggregate $\gamma$ and changes in the volatility of the aggregate bond returns. The fact that the VIX index, measured from index options, is the most important variable in explaining changes in aggregate illiquidity of corporate bonds is rather intriguing. Indeed, from an aggregate perspective, this implies that the sources of our estimated bond market illiquidity are not contained just in the bond market. This raises the possibility of illiquidity being an additional source of systemic risk, as examined by Chordia, Roll, and Subrahmanyam (2000) and Pastor and Stambaugh (2003) for the equity market.

Fourth, we examine the asset-pricing implications of bond illiquidity. We find that our illiquidity measure $\gamma$ explains the cross-sectional variation of average bond yield spreads with large economic significance. Controlling for bond rating categories, we perform monthly crosssectional regressions of bond yield spreads on bond $\gamma$. We find a coefficient of 0.4220 with a 
t-stat of 3.95 using Fama and MacBeth (1973) standard errors. Given that the cross-sectional standard deviation of $\gamma$ is 0.9943 , our result implies that for two bonds in the same rating category, a two standard deviation difference in their $\gamma$ leads to a difference in their yield spreads as large as 84 bps. This is comparable to the difference in yield spreads between Baa and Aaa/Aa bonds, which is over 77 bps in our sample. In contrast, quoted bid-ask spreads have rather limited, if any, economic significance in explaining the cross-sectional average yield spreads. Moreover, the economic significance of our illiquidity measure remains robust in its magnitude and statistical significance after we control for a spectrum of variables related to the bond's fundamental information as well as bond characteristics. In particular, liquidity related variables such as bond age, issuance size, quoted bid-ask spread, and average trade size do not change this result in a significant way.

In addition to the main results summarized above, we provide detailed analyses of our illiquidity measure to further shed light on the nature of illiquidity in corporate bonds. We explore the dynamic property of illiquidity by estimating the magnitude of price reversals after skipping one or several trades. We find significant price reversals even after skipping a trade, indicating a mean-reversion in price changes that lasts for more than one trade. ${ }^{4}$ We also find that negative price changes, likely caused by excess selling pressure, are followed by stronger reversals than positive price changes, resulting in an asymmetry in $\gamma \cdot{ }^{5}$ We find that price changes associated with large trades exhibit weaker reversals than those associated with small trades, and this effect is robust after controlling for the overall bond liquidity. Although this result suggests a strong link between liquidity and trade sizes, it is, however, difficult to interpret this negative relation between $\gamma$ and trade sizes simply as more liquidity for larger trades, since both trade sizes and prices are endogenous.

Our paper is related to the growing literature on the impact of liquidity on corporate bond yields. Using illiquidity proxies that include quoted bid-ask spreads and the percentage of zero returns, Chen, Lesmond, and Wei (2007) find that more illiquid bonds earn higher yield spreads. Using nine liquidity proxies including issuance size, age, missing prices, and yield volatility, Houweling, Mentink, and Vorst (2003) reach similar conclusions for euro corporate bonds. de Jong and Driessen (2005) find that systematic liquidity risk factors for the Treasury bond and equity markets are priced in corporate bonds, and Downing, Underwood, and Xing

\footnotetext{
${ }^{4}$ This is consistent with the fact that our $\gamma$ measured at the daily level, capturing this persistent transactionlevel mean-reversion cumulatively, yields a higher magnitude than its counterpart at the transaction level.

${ }^{5}$ Such an asymmetry was described as a characteristic of the impact of illiquidity on prices by Huang and Wang (2007). Our results provide an interesting empirical test of this proposition.
} 
(2005) address a similar question. Using a proprietary dataset on institutional holdings of corporate bonds, Nashikkar, Mahanti, Subrahmanyam, Chacko, and Mallik (2008) and Mahanti, Nashikkar, and Subrahmanyam (2008) propose a measure of latent liquidity and examine its connection with the pricing of corporate bonds and credit default swaps.

We contribute to this growing body of literature by proposing a measure of illiquidity that is theoretically motivated and empirically more direct. Moreover, the degree of illiquidity captured by our illiquidity measure is significantly higher in magnitude than that implied by the quoted or estimated bid-ask spreads. We are able to establish a connection between our measure of illiquidity and the commonly used liquidity proxies such as age, issuance and trading activities. But more importantly, our illiquidity measure contains information above and beyond these proxies in explaining, for example, the average bond yield spreads across a broad cross-section of bonds. Finally, the close connection between our aggregate illiquidity measure and overall market conditions is a clear indication that our measure indeed extracts useful information about illiquidity from the transaction-level data. We hope that the properties we uncover in this paper about the illiquidity of corporate bonds can provide a basis to further analyze its importance to the efficiency of the bond market.

The paper is organized as follows. Section 2 describes the data used in our analysis and provides summary statistics. The main results of our paper are reported in Section 3, and Section 4 provides further analyses of our illiquidity measure. Section 5 compares our illiquidity measure with the effect of bid-ask spreads. Section 6 concludes.

\section{Data Description and Summary}

The main data set used for this paper is FINRA's TRACE (Transaction Reporting and Compliance Engine). This data set is a result of recent regulatory initiatives to increase the price transparency in secondary corporate bond markets. FINRA, formerly the NASD, is responsible for operating the reporting and dissemination facility for over-the-counter corporate bond trades. On July 1, 2002, the NASD began Phase I of bond transaction reporting, requiring that transaction information be disseminated for investment grade securities with an initial issue size of $\$ 1$ billion or greater. Phase II, implemented on April 14, 2003, expanded reporting requirements, bringing the number of bonds to approximately 4,650. Phase III, implemented completely on February 7, 2005, required reporting on approximately $99 \%$ of all public transactions. Trade reports are time-stamped and include information on the clean price and par value traded, although the par value traded is truncated at $\$ 1$ million for speculative grade 
bonds and at $\$ 5$ million for investment grade bonds.

In our study, we drop the early sample period with only Phase I coverage. We also drop all of the Phase III only bonds. We sacrifice in these two dimensions in order to maintain a balanced sample of Phase I and II bonds from April 14, 2003 to December 31, 2007. Of course, new issuances and retired bonds generate some time variation in the cross-section of bonds in our sample. After cleaning up the data, we also take out the repeated inter-dealer trades by deleting trades with the same bond, date, time, price, and volume as the previous trade. ${ }^{6}$ We further require the bonds in our sample to have frequent enough trading so that the illiquidity measure can be constructed from the trading data. Specifically, during its existence in the TRACE data, a bond must trade on at least $75 \%$ of its relevant business days in order to be included in our sample. Finally, to avoid bonds that show up just for several months and then disappear from TRACE, we require the bonds in our sample to be in existence in the TRACE data for at least one full year.

Table 1 summarizes our sample, which consists of frequently traded Phase I and II bonds from April 2003 to December 2007. There are 1,249 bonds in our full sample, although the total number of bonds do vary from year to year. The increase in the number of bonds from 2003 to 2004 could be a result of how NASD starts its coverage of Phase III bonds, while the gradual reduction of number of bonds from 2004 through 2007 is a result of matured or retired bonds.

The bonds in our sample are typically large, with a median issuance size of $\$ 700$ million, and the representative bonds in our sample are investment grade, with a median rating of 6 , which translates to Moody's A2. The average maturity is close to 7 years and the average age is about 4 years. Over time, we see a gradual reduction in maturity and increase in age. This can be attributed to our sample selection which excludes bonds issued after February 7, 2005, the beginning of Phase III. ${ }^{7}$ Given our selection criteria, the bonds in our sample are more frequently traded than a typical bond. The average monthly turnover - the bond's monthly trading volume as a percentage of its issuance size - is $7.83 \%$, the average number of trades in a month is 174 . The average trade size is $\$ 448,000$.

In addition to the TRACE data, we use CRSP to obtain stock returns for the market and

\footnotetext{
${ }^{6}$ This includes cleaning up withdrawn or corrected trades, dropping trades with special sale conditions or special prices, and correcting for obvious mis-reported prices.

${ }^{7}$ We will discuss later the effect, if any, of this sample selection on our results. An alternative treatment is to include in our sample those newly issued bonds that meet the Phase II criteria, but this is difficult to implement since the Phase II criteria are not precisely specified by NASD.
} 


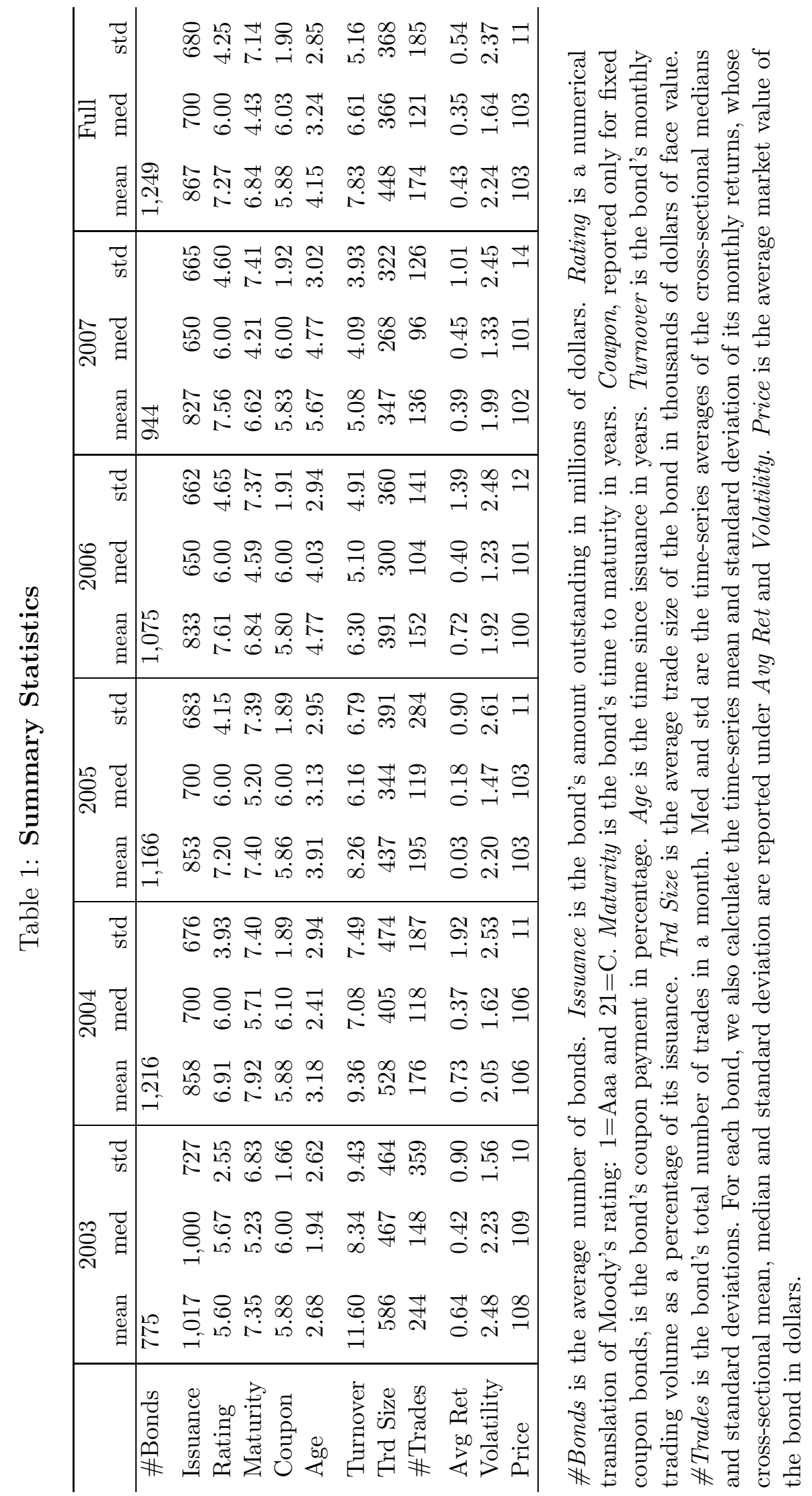


the respective bond issuers. We use FISD to obtain bond-level information such as issue date, issuance size, coupon rate, and credit rating, as well as to identify callable, convertible and putable bonds. We use Bloomberg to collect the quoted bid-ask spreads for the bonds in our sample, from which we have data for 1,212 out of the 1,249 bonds in our sample. We use Datastream to collect Lehman Bond indices to calculate the default spread and returns on the aggregate corporate bond market. To calculate yield spreads for individual corporate bonds, we obtain Treasury bond yields from the Federal Reserve, which publishes constant maturity Treasury rates for a range of maturities. Finally, we obtain the VIX index from CBOE.

\section{Main Results}

The main results of our paper center around our proposed measure of illiquidity: its main empirical properties and its asset-pricing implications. Section 3.1 motivates and formalizes our measure of illiquidity and reports its estimates for individual bonds. Section 3.2 examines the cross-sectional properties of our illiquidity measure, focusing in particular on its connection with various bond characteristics. Section 3.3 analyzes the time-series variation of our illiquidity measure with a focus on the commonality of bond illiquidity and its potential relation with changing market conditions. Finally, Section 3.4 explores the asset-pricing implications of illiquidity by examining the extent to which our measure of illiquidity can help explain the cross-sectional variation in corporate bond yield spreads.

\subsection{Measure of Illiquidity}

In the absence of a theory, a definition of illiquidity and its quantification remain imprecise. But two properties of illiquidity are clear. First, it arises from market frictions, such as costs and constraints for trading and capital flows; second, its impact to the market is transitory. ${ }^{8}$ Our empirical measure of illiquidity is motivated by these two properties.

Let $P_{t}$ denote the clean price of a bond at time $t$. We start by assuming that $P_{t}$ consists of two components:

$$
P_{t}=F_{t}+u_{t} .
$$

The first component $F_{t}$ is its fundamental value - the price in the absence of frictions, which follows a random walk; the second component $u_{t}$ comes from the impact of illiquidity,

\footnotetext{
${ }^{8}$ In a recent paper, Vayanos and Wang (2008) provide a unified theoretical model for liquidity, which relates illiquidity with different forms of market frictions. Huang and Wang (2007) consider a model in which trading costs give rise to illiquidity in the market endogenously and show that it leads to transitory deviations in prices from fundamentals.
} 
which is transitory. ${ }^{9}$ In such a framework, the magnitude of the transitory price component $u_{t}$ characterizes the level of illiquidity in the market. Our measure of illiquidity is aimed at extracting the transitory component in the observed price $P_{t}$. Specifically, let $\Delta P_{t}=P_{t}-P_{t-1}$ be the price change from $t-1$ to $t$. We define the measure of illiquidity $\gamma$ by

$$
\gamma=-\operatorname{Cov}\left(\Delta P_{t}, \Delta P_{t+1}\right)
$$

With the assumption that the fundamental component $F_{t}$ follows a random walk, $\gamma$ depends only on the transitory component $u_{t}$, and it increases with the magnitude of $u_{t}$.

Several comments are in order before our proceed with our analysis of $\gamma$. First, other than being transitory, we know little about the dynamics of $u_{t}$. For example, when $u_{t}$ follows an $\operatorname{AR}(1)$ process, we have $\gamma=(1-\rho)^{2} \sigma^{2} /(1+\rho)$, where $\sigma$ is the instantaneous volatility of $u_{t}$, and $\rho$ is its persistence coefficient. ${ }^{10}$ In this case, while $\gamma$ does provide a simple gauge of the magnitude of $u_{t}$, it combines various aspects of $u_{t}$. Second, in terms of measuring illiquidity, other aspects of $u_{t}$ that are not fully captured by $\gamma$ may also matter. In other words, $\gamma$ itself gives only a partial measure of illiquidity. Third, given the potential richness in the dynamics of $u_{t}, \gamma$ will in general depend on the horizon over which we measure price changes. And this horizon effect is important because $\gamma$ measured over different horizons may capture different aspects of $u_{t}$ or illiquidity. For most of our analysis, we will use either trade-by-trade prices or end of the day prices in estimating $\gamma$. Consequently, our $\gamma$ estimate captures more of the high frequency components in transitory price movements.

Table 2 summarizes the illiquidity measure $\gamma$ for the bonds in our sample. ${ }^{11}$ Focusing first on Panel A, in which $\gamma$ is estimated bond-by-bond using either trade-by-trade or daily data, we see an illiquidity measure of $\gamma$ that is important both economically and statistically. For the full sample period from 2003 through 2007, our illiquidity measure $\gamma$ has a cross-sectional average of 0.5814 with a robust t-stat of 22.23 when estimated using trade-by-trade data, and an average of 0.9080 with a robust t-stat of 29.13 using daily data. ${ }^{12}$ More importantly, the

\footnotetext{
${ }^{9}$ Such a separation assumes that the fundamental value $F_{t}$ carries no time-varying risk premium. This is a reasonable assumption over short horizons. It is equivalent to assuming that high frequency variations in expected returns are ultimately related to market frictions - otherwise, arbitrage forces would have driven them away. To the extent that illiquidity can be viewed a manifestation of these frictions, price movements giving rise to high frequency variations in expected returns should be included in $u_{t}$. Admittedly, a more precise separation of $F_{t}$ and $u_{t}$ must rely on a pricing theory incorporating frictions or illiquidity. See, for example, Vayanos and Wang (2008).

${ }^{10}$ The persistent coefficient $\rho$ is less than 1 given that $u_{t}$ is transitory.

${ }^{11}$ To be included in our sample, the bond must trade on at least $75 \%$ of business days and at least 10 observations of the paired price changes, $\left(\Delta P_{t}, \Delta P_{t-1}\right)$, are required to calculate $\gamma$.

${ }^{12}$ The robust t-stats are calculated using standard errors that are corrected for cross-sectional and time-
} 
significant mean estimate of $\gamma$ is not generated by just a few highly illiquid bonds. Using trade-by-trade data, the cross-sectional median of $\gamma$ is 0.3598 , and $100 \%$ of the bonds have a statistically significant $\gamma$ (the t-stat of $\gamma$ greater than or equal to 1.96); using daily data, the cross-sectional median of $\gamma$ is 0.5533 and over $99 \%$ of the bonds have a statistically significant $\gamma$. Moreover, breaking our full sample by year shows that the illiquidity measure $\gamma$ is important and stable across years.

Table 2: Measure of Illiquidity $\gamma=-\operatorname{Cov}\left(P_{t}-P_{t-1}, P_{t+1}-P_{t}\right)$

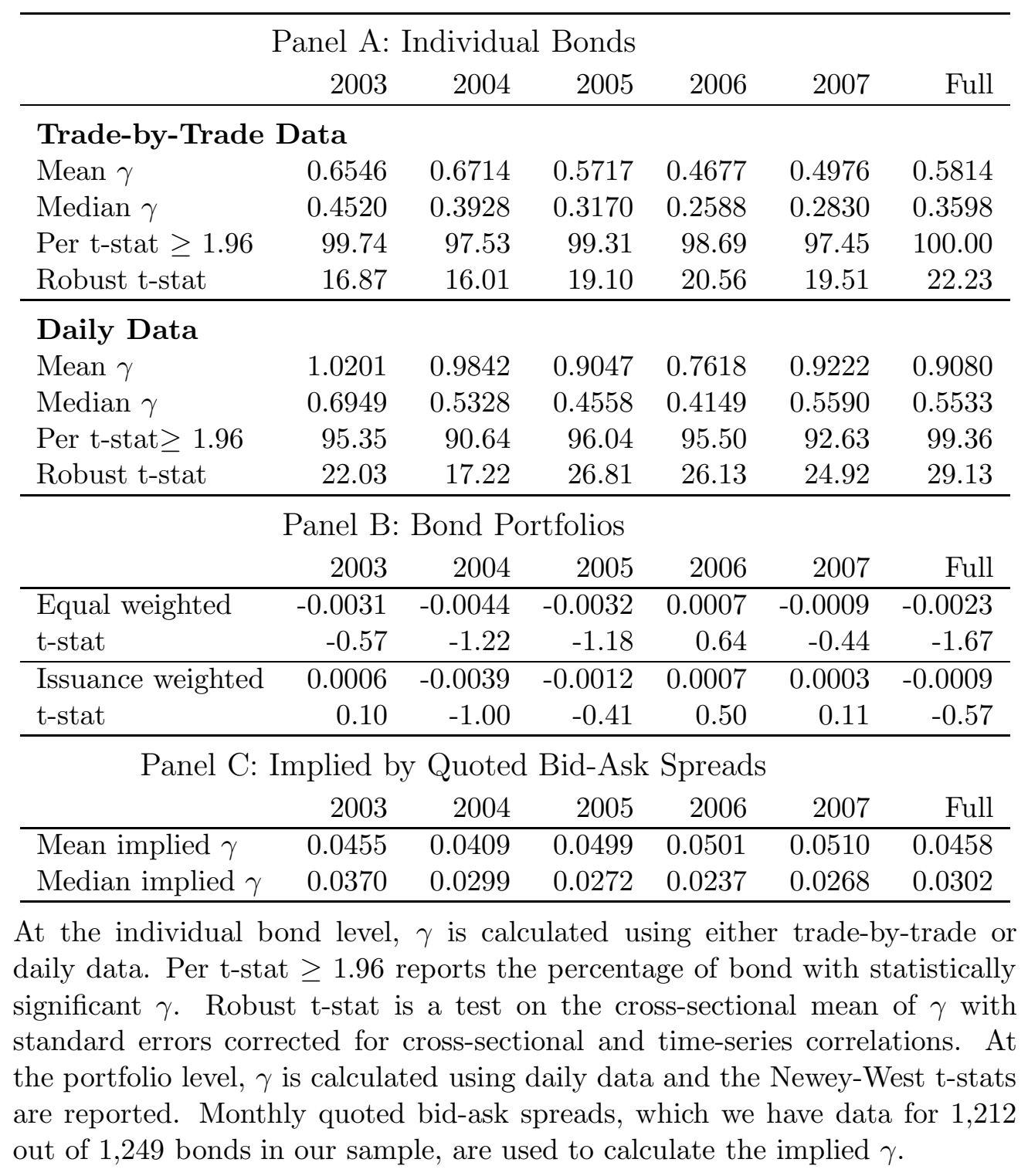

series correlations. Specifically, the moment condition for estimating $\gamma$ is $\hat{\gamma}+\Delta P_{t}^{i} \Delta P_{t-1}^{i}=0$ for all bond $i$ and time $t$, where $\Delta P$ is demeaned. We can then correct for cross-sectional and time-series correlations in $\Delta P_{t}^{i} \Delta P_{t-1}^{i}$ using standard errors clustered by bond and day. 
As a comparison to the level of illiquidity for individual bonds, Panel B of Table 2 reports $\gamma$ measured using equal- or issuance-weighted portfolios constructed from the same cross-section of bonds and for the same sample period. In contrast to its counterpart at the individual bond level, $\gamma$ at the portfolio level is slightly negative, rather small in magnitude, and statistically insignificant. This implies that the transitory component extracted by our $\gamma$ measure is idiosyncratic in nature and gets diversified away at the portfolio level. It does not imply, however, that the illiquidity in corporate bonds lacks a systematic component, which we will examine later in Section 3.3.

Panel $\mathrm{C}$ of Table 2 provides another and perhaps more important gauge of the magnitude of our estimated $\gamma$ for individual bonds. Using quoted bid-ask spreads for the same crosssection of bonds and for the same sample period, we estimate a bid-ask implied $\gamma$ for each bond by computing the magnitude of negative autocovariance that would have been generated by bid-ask bounce. For the full sample period, the cross-sectional mean of the implied $\gamma$ is 0.0458 and the median is 0.0302 , which are more than one order of magnitude smaller than the empirically observed $\gamma$ for individual bonds. As shown later in the paper, not only does the quoted bid-ask spread fail to capture the overall level of illiquidity, but it also fails to explain the cross-sectional variation in bond illiquidity and its asset pricing implications.

Although in the remainder of the paper we focus on extracting the transitory component at the trade-by-trade and daily frequencies, it is nevertheless interesting to provide a general picture of $\gamma$ over varying horizons. First, our result shows that the magnitude of the illiquidity measure $\gamma$ is stronger at the daily than the trade-by-trade horizon. Given that the autocovariance at the daily level cumulatively captures the mean-reversion at the tradeby-trade level, this implies that the mean-reversion at the trade-by-trade level persists for a few trades before fully dissipating, which we show in Section 4.1. Second, moving from the daily to weekly horizon, we find that the magnitude of $\gamma$ increases from an average level of 0.9080 to 1.0899 , although its statistical significance decreases somewhat to a robust t-stat of 16.81 , and $82.79 \%$ of the bonds in our sample have a positive and statistically significant $\gamma$ at this horizon. Third, extending to the bi-weekly and monthly horizons, $\gamma$ starts to decline in both magnitudes and statistical significance, equaling 0.9199 with a robust t-stat of 8.04 for bi-weekly, and 0.5076 with a robust t-stat of 2.18 for monthly horizons. At the individual bond level, the fraction of bonds that have positive and statistically significant $\gamma$ is $42.88 \%$ for bi-weekly, and only $16.5 \%$ for monthly horizons, respectively. Finally, at the six-week horizon, the magnitude of the estimate inches up a little from its monthly counterpart, but there is no 
longer any statistical significance.

As mentioned earlier in the section, the transitory component $u_{t}$ might have richer dynamics than what can be offered by a simple $\operatorname{AR}(1)$ structure for $\Delta u_{t}$. By extending $\gamma$ over various horizons, we are able to uncover some of the dynamics. We show in Section 4.1 that at the trade-by-trade level $\Delta u_{t}$ is by no means a simple $\operatorname{AR}(1)$. Likewise, in addition to the mean-reversion at the daily horizon that is captured in this paper, the transitory component $u_{t}$ may also have a slow moving mean-reversion component at a longer horizon. To examine this issue more thoroughly is an interesting topic, but requires time-series data for a longer sample period than ours. ${ }^{13}$

\subsection{Illiquidity and Bond Characteristics}

Our sample includes a broad cross-section of bonds, which allows us to examine the connection between our illiquidity measure $\gamma$ and various bond characteristics, some of which are known to be linked to bond liquidity. The cross-sectional variation in our illiquidity measure $\gamma$ and bond characteristics are reported in Table 3. We use daily data to construct yearly estimates for $\gamma$ for each bond and perform yearly cross-sectional regressions on various bond characteristics. Reported in square brackets are the t-stat's calculated using the Fama and MacBeth (1973) standard errors.

We find that older bonds on average have higher $\gamma$, and the results are robust regardless of which control variables are used in the regression. On average, a bond that is one-year older is associated with an increase of 0.0726 in its $\gamma$, which accounts for $8 \%$ of the full-sample average of $\gamma$. Given that the age of a bond has been widely used in the fixed-income market as a proxy for illiquidity, it is important that we establish this connection between our illiquidity measure $\gamma$ and age. Similarly, we find that bonds with smaller issuance tend to have larger $\gamma$. We also find that bonds with longer time to maturity and lower credit rating typically have higher $\gamma$.

Using weekly bond returns, we also estimate, for each bond, its beta's on the aggregate stock- and bond-market returns, using the CRSP value-weighted index as a proxy for the stock market and the Lehman US Bond Index as a proxy for the bond market. We find that

\footnotetext{
${ }^{13}$ By using monthly bid prices from 1978 to 1998, Khang and King (2004) report contrarian patterns in corporate bond returns over horizons of one to six months. Instead of examining autocovariance in bond returns, their focus is on the cross-sectional effect. Sorting bonds by their past monthly (or bi-monthly up to 6 months) returns, they find that past winners under perform past losers in the next month (or 2-month up to 6 months). Their result, however, is relatively weak and is significant only in the early half of their sample and goes away in the second half of their sample (1988-1998).
} 
Table 3: Cross-Sectional Variation in $\gamma$ and Bond Characteristics

\begin{tabular}{|c|c|c|c|c|c|c|c|c|}
\hline Cons & $\begin{array}{l}0.8795 \\
{[21.93]}\end{array}$ & $\begin{array}{l}0.8775 \\
{[23.28]}\end{array}$ & $\begin{array}{l}0.8671 \\
{[14.97]}\end{array}$ & $\begin{array}{l}0.8763 \\
{[23.03]}\end{array}$ & $\begin{array}{l}0.8830 \\
{[22.83]}\end{array}$ & $\begin{array}{l}0.8786 \\
{[22.66]}\end{array}$ & $\begin{array}{l}0.8948 \\
{[17.42]}\end{array}$ & $\begin{array}{l}0.9271 \\
{[25.12]}\end{array}$ \\
\hline Age & $\begin{array}{r}0.0726 \\
{[4.37]}\end{array}$ & $\begin{array}{r}0.0523 \\
{[6.18]}\end{array}$ & $\begin{array}{r}0.0517 \\
{[4.24]}\end{array}$ & $\begin{array}{r}0.0464 \\
{[4.97]}\end{array}$ & $\begin{array}{r}0.0326 \\
{[3.95]}\end{array}$ & $\begin{array}{r}0.0571 \\
{[5.98]}\end{array}$ & $\begin{array}{r}0.0722 \\
{[3.44]}\end{array}$ & $\begin{array}{r}0.0719 \\
{[3.64]}\end{array}$ \\
\hline Maturity & $\begin{array}{l}0.0708 \\
{[11.05]}\end{array}$ & $\begin{array}{l}0.0424 \\
{[19.59]}\end{array}$ & $\begin{array}{r}0.0401 \\
{[3.12]}\end{array}$ & $\begin{array}{l}0.0461 \\
{[11.04]}\end{array}$ & $\begin{array}{l}0.0481 \\
{[10.96]}\end{array}$ & $\begin{array}{r}0.0450 \\
{[9.80]}\end{array}$ & $\begin{array}{l}0.0651 \\
{[13.45]}\end{array}$ & $\begin{array}{l}0.0688 \\
{[17.36]}\end{array}$ \\
\hline $\ln$ (Issuance) & $\begin{array}{r}-0.1951 \\
{[-5.87]}\end{array}$ & $\begin{array}{r}-0.1373 \\
{[-3.23]}\end{array}$ & $\begin{array}{r}-0.1294 \\
{[-5.31]}\end{array}$ & $\begin{array}{r}-0.1368 \\
{[-3.57]}\end{array}$ & $\begin{array}{r}-0.0257 \\
{[-1.05]}\end{array}$ & $\begin{array}{r}-0.1551 \\
{[-3.81]}\end{array}$ & $\begin{array}{r}-0.2129 \\
{[-6.12]}\end{array}$ & $\begin{array}{r}-0.2340 \\
{[-7.87]}\end{array}$ \\
\hline Rating & $\begin{array}{r}0.0415 \\
{[8.05]}\end{array}$ & $\begin{array}{r}0.0164 \\
{[3.95]}\end{array}$ & $\begin{array}{r}0.0105 \\
{[1.58]}\end{array}$ & $\begin{array}{r}0.0232 \\
{[3.03]}\end{array}$ & $\begin{array}{r}0.0314 \\
{[3.35]}\end{array}$ & $\begin{array}{r}0.0190 \\
{[2.40]}\end{array}$ & $\begin{array}{r}0.0403 \\
{[2.77]}\end{array}$ & $\begin{array}{r}0.0537 \\
{[6.82]}\end{array}$ \\
\hline beta (stock) & $\begin{array}{r}0.4389 \\
{[4.34]}\end{array}$ & $\begin{array}{r}0.1536 \\
{[0.70]}\end{array}$ & $\begin{array}{r}0.24 \\
{[1.13]}\end{array}$ & & & & & \\
\hline beta (bond) & $\begin{array}{r}-0.0237 \\
{[-0.90]}\end{array}$ & $\begin{array}{r}0.0351 \\
{[0.69]}\end{array}$ & $\begin{array}{r}0.0307 \\
{[0.59]}\end{array}$ & & & & & \\
\hline $\operatorname{sig}(e)$ & & $\begin{array}{r}0.4730 \\
{[4.37]}\end{array}$ & & $\begin{array}{r}0.4581 \\
{[4.04]}\end{array}$ & $\begin{array}{r}0.4120 \\
{[3.82]}\end{array}$ & $\begin{array}{r}0.4397 \\
{[3.79]}\end{array}$ & & \\
\hline $\operatorname{sig}\left(e^{\text {firm }}\right)$ & & & $\begin{array}{r}-0.0357 \\
{[-0.42]}\end{array}$ & & & & & \\
\hline $\operatorname{sig}\left(e^{\text {firm res }}\right)$ & & & $\begin{array}{l}0.6570 \\
{[11.31]}\end{array}$ & & & & & \\
\hline Turnover & & & & $\begin{array}{r}-0.0165 \\
{[-2.60]}\end{array}$ & & & & \\
\hline $\ln (\operatorname{Trd}$ Size $)$ & & & & & $\begin{array}{l}-0.2350 \\
{[-10.15]}\end{array}$ & & & \\
\hline $\ln (\#$ Trades $)$ & & & & & & $\begin{array}{r}0.0571 \\
{[1.66]}\end{array}$ & & \\
\hline Quoted BA $\gamma$ & & & & & & & $\begin{array}{r}2.0868 \\
{[2.61]}\end{array}$ & \\
\hline CDS Dummy & & & & & & & & $\begin{array}{r}-0.0456 \\
{[-1.90]}\end{array}$ \\
\hline R-sqd (\%) & 49.11 & 62.68 & 74.46 & 61.79 & 63.86 & 61.46 & 47.43 & 45.61 \\
\hline
\end{tabular}

Yearly Fama-MacBeth regression with $\gamma$ as the dependent variable. T-stats are reported in square brackets using Fama-MacBeth standard errors with serial correlations corrected using Newey-West. Issuance is the bond's amount outstanding in millions of dollars. Rating is a numerical translation of Moody's rating: $1=$ Aaa and $21=\mathrm{C}$. Maturity is the bond's time to maturity in years. Turnover is the bond's monthly trading volume as a percentage of its issuance. Trd Size is the average trade size of the bond in thousands of dollars of face value. \#Trades is the bond's total number of trades in a month. beta(stock) and beta(bond) are obtained by regressing weekly bond returns on weekly returns on the CRSP value-weighted index and the Lehman US bond index, and $\operatorname{sig}(e)$ is the standard deviation of the residual. For firms with more than 10 bonds, $\operatorname{sig}(\mathrm{e})$ is further decomposed into a firm-level $\operatorname{sig}\left(e^{\text {firm }}\right)$ and the residual $\operatorname{sig}\left(e^{\text {firm res }}\right)$. Quoted $B A \gamma$ is the $\gamma$ implied by the quoted bid-ask spreads. $C D S$ Dummy is 1 if the bond has credit default swaps traded on its issuer. 
while $\gamma$ cannot be explained by the cross-sectional variation in the bond beta, it is positively related to the stock beta. But this result goes away after adding the volatility, sig(e), of the idiosyncratic component of bond returns. Specifically, our results show that a bond with a higher idiosyncratic volatility has higher $\gamma$. For a sub-sample of our bonds whose issuer issues more than 10 bonds, we can further decompose the idiosyncratic volatility into a firmlevel component and a bond-specific component. We find that the firm-specific component is not related to our illiquidity measure $\gamma$, while the bond-specific component exhibits a strong connection to our illiquidity measure. Interestingly, bond ratings are not significantly related to $\gamma$ in this regression, although this could be because of the specific sub-sample.

Given that we have transaction-level data, we can also examine the connection between our illiquidity measure and bond trading activity. We find that, by far, the most interesting variable is the average trade size of a bond. In particular, bonds with smaller trade sizes have higher illiquidity measure $\gamma$.

To examine the cross-sectional connection between our illiquidity measure and the quoted bid-ask spreads, we use the quoted bid-ask spreads for each bond in our sample to calculate the bid-ask spread implied autocovariance, or bid-ask implied $\gamma$. We find a positive relation between our $\gamma$ measure and the $\gamma$ measure implied by the quoted bid-ask spread. The regression coefficient is on average around 2 and is statistically significant. The magnitude of the coefficient implies that one unit difference in $\gamma$ implied by quoted bid-ask spreads gets amplified to twice the difference in our measure of $\gamma$. Adding the bid-ask implied $\gamma$ as an explanatory variable, however, does not alter the relation between our $\gamma$ measure and liquidity-related bond characteristics such as age and size. Overall, we find that the magnitude of illiquidity captured by our $\gamma$ measure is related to but goes beyond the information contained in the quoted bid-ask spreads.

Finally, we introduce a CDS dummy, which is one if the bond issuer has credit default swaps traded on it, to examine whether or not there is a difference in our illiquidity measure for bonds with and without CDS traded on their issuers. About $85 \%$ of the bonds in our sample have traded CDS and our results show that, after controlling for bond age, maturity, issuance size and rating, such bonds on average do have slightly lower $\gamma$, although with marginal economic and statistical significance. 


\subsection{Commonality in Illiquidity and Market Conditions}

We next examine the time variation of illiquidity in the bond market. From Table 2, we see a steady reduction in the annual $\gamma$ averaged over all bonds in our sample from 2003 through 2006. For example, the average $\gamma$ using daily data is 1.0204 in 2003, which decreases monotonically to 0.7818 in 2006, suggesting an overall improvement of liquidity in the bond market from 2003 through 2006. During 2007, however, the average $\gamma$ jumped back to 0.9222, reflecting worsening liquidity in the market. ${ }^{14}$ Our focus in this section is on the time variation beyond this simple time trend and its association with the conditions in the credit market. For this, we turn our attention to monthly fluctuations in the illiquidity measure $\gamma$.

Monthly illiquidity measures $\gamma$ are calculated for each bond using daily data within that month. Aggregating $\gamma$ across all bonds, we plot in Figure 1 the time-series of the monthly aggregate illiquidity measure $\gamma$ and the lower and upper bounds of its $95 \%$ confidence interval calculated using robust standard errors that take into account both time-series and crosssectional correlations. It is clear that the aggregate $\gamma$ exhibits significant time variation, which suggests common movements in illiquidity across individual bonds.

In particular, after decreasing markedly but relatively smoothly during 2003 and the first half of 2004, it reversed its trend and started to climb up in late 2004 and then spiked in April/May 2005. This rise in $\gamma$ coincides with the downgrade of Ford and GM to junk status in early May 2005, which rattled the credit market. The illiquidity measure $\gamma$ quieted down somewhat through 2006, and then in August 2007, it rose sharply to an unprecedented level since the beginning of in our sample. August 2007 is when the sub-prime mortgage crisis hit the market and the credit conditions in the U.S. worsened in a precipitous fashion. Compared with its value in late 2006, which was below 0.8, the quick rise to a level of 1.37 in August 2007 was quite dramatic. Even relative to July 2007, when the aggregate $\gamma$ was at a level of 0.9727 , the upward jump was an extreme event. For our sample, the standard deviation of monthly changes in aggregate $\gamma$ is 0.1084 , making the monthly jump from July to August a close to four-standard-deviation event. In September and October, the illiquidity measure $\gamma$ came

\footnotetext{
${ }^{14}$ By focusing only on Phase I and II bonds in TRACE to maintain a reasonably balanced sample, we did not include bonds that were included only after Phase III, which was fully implemented on February 7, 2005. Consequently, new bonds issued after that date were excluded from our sample, even though some of them would have been eligible for Phase II had they been issued earlier. As a result, starting from February 7, 2005, we have a population of slowly aging bonds. Since $\gamma$ is positively related to age, the overall downward trend in $\gamma$ would have been more pronounced had we been able to maintain a more balanced sample. It should be mentioned that the sudden increases in aggregate $\gamma$ during crises are too large to be explained by the slow aging process. Finally, to avoid regressing trend on trend, the time-series regression results presented later in this section are based on regressing changes on changes.
} 


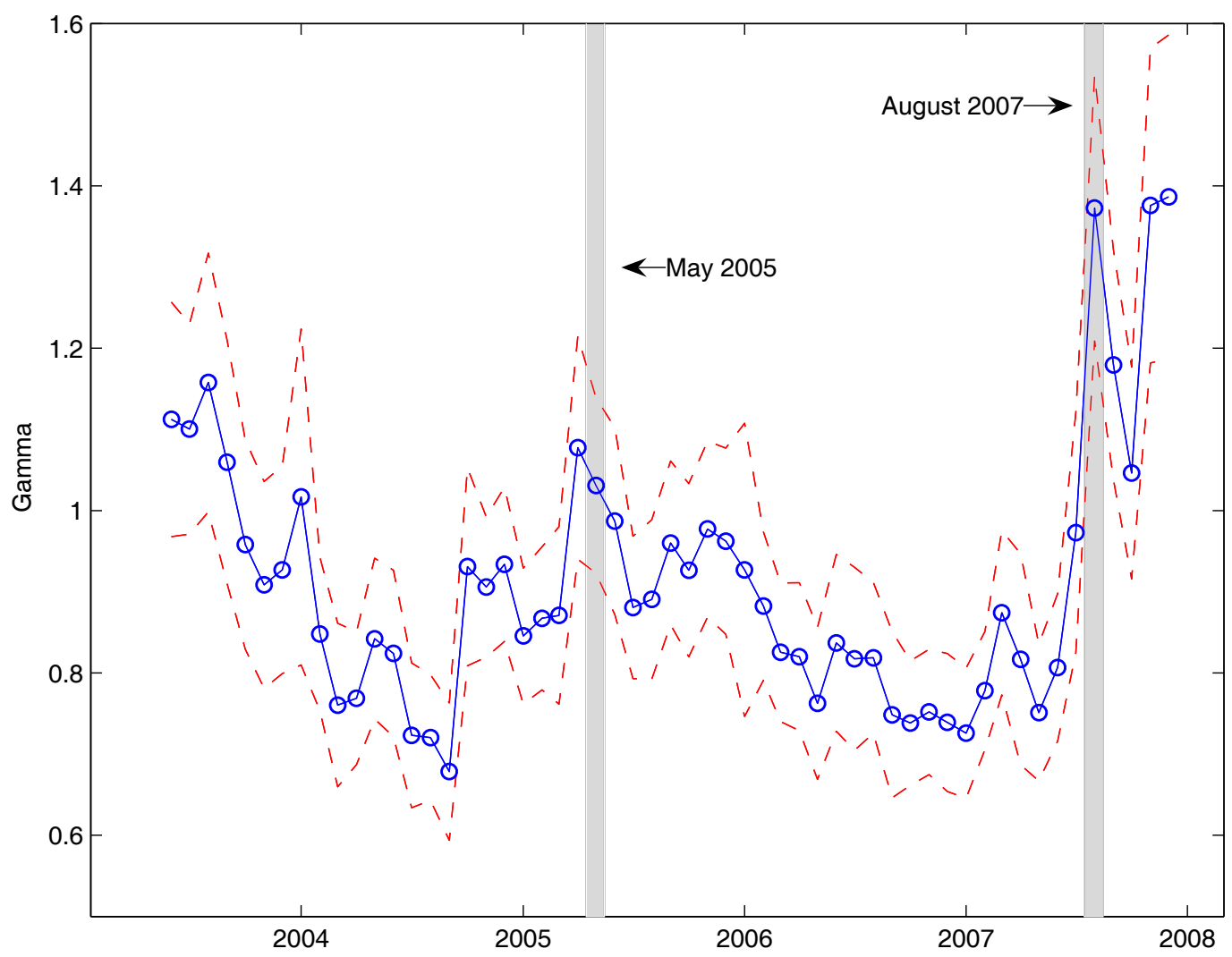

Figure 1: Monthly time-series of $\gamma$, averaged across all bonds. For each bond and month, daily data is used to estimate $\gamma$. The dashed lines are the upper and lower bounds of the $95 \%$ confidence interval, using robust standard errors clustered by bond and day.

down somewhat. But then, on October 24, Merrill Lynch reported the biggest quarterly loss in its 93 -year history after taking $\$ 8.4$ billion of write-downs, almost double the firm's forecast three weeks before. Less than a week later, the CEO of Merrill resigned. This was followed by Citigroup's announcement of write-downs of even larger magnitudes and the resignation of its CEO in early November. Not surprisingly, our illiquidity measure $\gamma$ quickly jumped up again in November and December 2007 to an all time high level of 1.39.

The fact that $\gamma$ increased drastically during the two periods of credit market turmoil indicates that not only does bond market illiquidity vary over time, but, more importantly, it also varies together with the changing conditions of the market. In Figure 2, we plot the average $\gamma$ along with several variables that are known to be linked to market conditions. To capture the conditions of the credit market, we use default spread, measured as the difference in yields between AAA- and BBB-rated corporate bonds, using the Lehman US Corporate Intermediate Indices. To capture the overall market condition, we use the CBOE VIX index, which is also known as the "fear gauge" of the market. To capture the overall volatility of the 


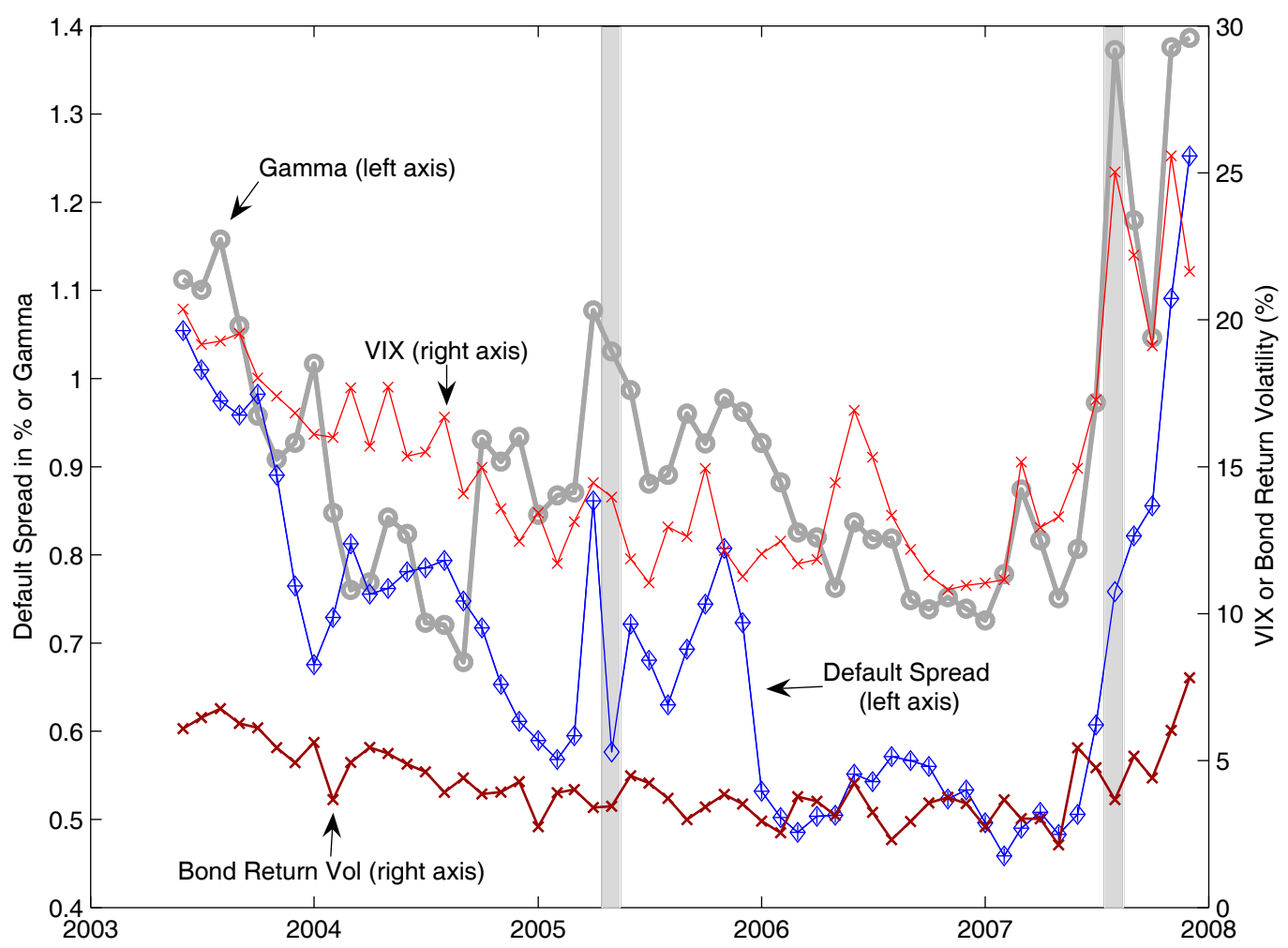

Figure 2: Monthly time-series of $\gamma$ along with CBOE VIX index, default spread, and bond return volatility.

corporate bond market, we construct monthly estimates of annualized bond return volatility using daily returns to the Lehman US Investment Grade Corporate Index. Comparing the time variation in these variables with that of our aggregate $\gamma$, we have several observations.

First, there does not seem to be an obvious link between $\gamma$ and the volatility of bond returns. In fact, as shown in Table 4 , regressing changes in $\gamma$ on contemporaneous changes in the bond volatility, the t-stat of the slope coefficient is 0.71 and the R-squared of the regression is $0.45 \%$. This is somewhat surprising. To the extent that volatility affects the risks in market making, one might expect a positive relation between illiquidity and return volatility. Second, contrasting its lack of comovement with bond volatility, the aggregate $\gamma$ comoves with VIX in a rather significant way. Regressing changes in $\gamma$ on contemporaneous changes in VIX, we obtain a slope coefficient of 0.0312 with a t-stat of 3.46 (adjusted for serial correlation using Newey-West). The R-squared of the OLS regression is 39.53\%, and the adjusted Rsquared is $37.96 \%$. Third, the aggregate $\gamma$ also comoves with the default spread in a positive way. Regressing changes in $\gamma$ on contemporaneous changes in the default spread, the slope coefficient is 0.4757 with a t-stat of 2.31 and the adjusted R-squared is $13.92 \%$. By far, the 
connection between $\gamma$ and the CBOE VIX index seems to be the strongest, which is quite interesting given that one variable is constructed using transaction-level corporate bond data and the other using index options.

Table 4: Time Variation in $\gamma$ and Market Variables

\begin{tabular}{lrrrrrrr}
\hline Cons & 0.0035 & 0.0029 & 0.0066 & 0.0027 & 0.0159 & 0.0060 & 0.0126 \\
& {$[0.30]$} & {$[0.33]$} & {$[0.53]$} & {$[0.33]$} & {$[1.11]$} & {$[0.48]$} & {$[1.51]$} \\
Bond Volatility & 0.0079 & & & & & & 0.0063 \\
& {$[0.71]$} & & & & & & {$[0.72]$} \\
$\Delta$ VIX & & 0.0312 & & & & & 0.0270 \\
& & {$[3.46]$} & & & & & {$[3.02]$} \\
$\Delta$ Term Spread & & & 0.1010 & & & & 0.0210 \\
& & {$[1.57]$} & & & & {$[0.37]$} \\
$\Delta$ Default Spread & & & 0.4757 & & & 0.2100 \\
& & & {$[2.31]$} & & & {$[1.57]$} \\
Lagged Stock Return & & & & & -0.0125 & & -0.0087 \\
& & & & & {$[-2.31]$} & & {$[-3.07]$} \\
Lagged Bond Return & & & & & & -0.0215 & -0.0102 \\
& & & & & & {$[-3.52]$} & {$[-1.26]$} \\
Adj R-sqd (\%) & -1.43 & 37.96 & 0.44 & 13.92 & 7.15 & 2.74 & 43.51 \\
\hline
\end{tabular}

Monthly changes in $\gamma$ regressed on monthly changes in bond index volatility, VIX, term spread, default spread, and lagged stock and bond returns. The Newey-West t-stats are reported in square brackets.

We further examine in Table 4 the relation between monthly changes of our aggregate $\gamma$ and the performance of the aggregate stock and bond markets in the previous month. We find that our aggregate $\gamma$ typically increases after a poor performance in the aggregate bond or stock market. The slope coefficient is -0.0125 with a t-stat of -2.31 for the lagged stock return, and is -0.0215 with a t-stat of -3.52 for the lagged bond return. ${ }^{15}$ These results are consistent with the observation that liquidity is more likely to worsen following a down market.

The various market condition variables considered so far are closely inter-connected. To evaluate their relative importance, Table 4 also reports the result of the multivariate regression using all variables simultaneously to explain the monthly changes in aggregate $\gamma$. Both VIX and lagged stock returns remain significant, but the default spread and lagged bond returns fail to remain significant. It is quite intriguing that two variables measured from the same

\footnotetext{
${ }^{15}$ We use monthly excess stock and bond returns, with the one-month T-bill rate as the risk-free rate. It might also be interesting to observe that in the univariate regression, changes in VIX and lagged bond return have similar magnitudes of t-stat but very different R-squareds. This is because our t-stats are corrected for serial correlation using Newey-West. Our results imply that the regression residuals are positively autocorrelated in the regression involving changes in VIX, and negatively autocorrelated in the regression involving lagged bond return.
} 
market fail to explain our aggregate $\gamma$, while two other variables, one from index options and the other from the stock market, remain important.

Our time-series analysis of the aggregate illiquidity reveals two important properties of $\gamma$ as a measure of illiquidity for corporate bonds. First, there exists commonality in the illiquidity of individual bonds, which is reflected in the significant time variation in aggregate $\gamma$. Second, such common movements in bond market illiquidity are closely connected with overall market conditions in an important way.

In order to further explore the commonalities in bond market illiquidity, we conduct a principal component analysis for the changes in the $\gamma$ of individual bonds. In particular, we sort bonds by their age and issuance size into nine portfolios. We choose these two bond characteristics because they are known to be linked to bond liquidity. For each portfolio, we compute its aggregate $\gamma$ by averaging the bond level $\gamma$ (estimated monthly using daily data) across all bonds in the portfolio. Using monthly changes in the $\gamma$ 's for the nine age and size sorted portfolios, we estimate the variance-covariance matrix and compute its eigenvalues. The results are summarized in Table 5.

\section{Table 5: Principal Component Analysis of $\gamma$}

\begin{tabular}{|c|c|c|c|c|c|}
\hline \multicolumn{6}{|c|}{ Panel A: The Relative Importance of the PC's } \\
\hline & & PC1 & $\mathrm{PC} 2$ & $\mathrm{PC} 3$ & $\mathrm{PC} 4$ \\
\hline$\%$ Explai & & 30.32 & 21.05 & 17.68 & 11.01 \\
\hline Cumulat & re $\%$ & 30.32 & 51.37 & 69.05 & 80.06 \\
\hline \multicolumn{6}{|c|}{ Panel B: Factor Loadings on the First Four PC's } \\
\hline size & age & PC1 & $\mathrm{PC} 2$ & PC3 & $\mathrm{PC} 4$ \\
\hline $1=$ small & $1=$ young & 0.2817 & -0.0494 & 0.2421 & 0.3232 \\
\hline 1 & 2 & -0.0778 & 0.7943 & 0.5572 & 0.1330 \\
\hline 1 & 3 & 0.3659 & -0.0147 & -0.2269 & 0.5218 \\
\hline 2 & 1 & 0.1979 & -0.1125 & 0.2104 & 0.1809 \\
\hline 2 & 2 & 0.2930 & -0.0135 & -0.0905 & 0.4271 \\
\hline 2 & 3 & 0.5682 & -0.2876 & 0.4969 & -0.4674 \\
\hline 3 & 1 & 0.1130 & -0.0228 & 0.0823 & 0.2106 \\
\hline 3 & 2 & 0.1621 & -0.0459 & 0.1455 & 0.0165 \\
\hline $3=$ large & $3=$ old & 0.5420 & 0.5180 & -0.5021 & -0.3568 \\
\hline
\end{tabular}

The principal component analysis is performed on 9 portfolios of bonds sorted by age and issuance size.

The first principal component explains over $30 \%$ of the changes in the portfolio $\gamma$ 's, while the next three principal components explain $21 \%, 18 \%$ and $11 \%$ of the variation, respectively. The first two principal components collectively explain over $51 \%$ of the variation in portfolio 
$\gamma$ 's, and the first four principal components explain over $80 \%$. Examining the factor loadings of the first four principal components, we find no obvious link between them and the bond characteristics considered here. The first principal component, however, resembles our aggregate $\gamma$, with the exception of small-size and medium-age bonds whose factor loading is slightly negative.

\subsection{Bond Yield Spreads and Illiquidity}

We now examine the pricing implications of bond illiquidity. For this purpose, we focus on the bond yield spread, which is the difference between the corporate bond yield and the Treasury bond yield of the same maturity. For Treasury yields, we use the constant maturity rate published by the Federal Reserve and use linear interpolation whenever necessary. We perform monthly cross-sectional regressions of the yield spreads on the illiquidity measure $\gamma$, along with a set of control variables. We first report our results for our full sample of bonds, including both investment-grade and junk bonds, and then for only investment-grade bonds. Given that the Phase I and II bonds in TRACE are predominantly investment grade, this sub-sample analysis is important for us to rule out the possibility that our result is driven just by a handful of unrepresentative junk bonds.

The results for both investment-grade and junk bonds are reported in Table 6, where the tstat's are calculated using the Fama-MacBeth standard errors with serial correlation corrected using Newey and West (1987). To include callable bonds in our analysis, which constitute a large portion of our sample, we use a callable dummy, which is one if a bond is callable and zero otherwise. We exclude all convertible and putable bonds from our analysis. In addition, we also include three rating dummies for A, Baa, and junk ratings, respectively. The first column in Table 6 shows that the average yield spread of the Aaa and Aa bonds in our sample is 70.62 bps, relative to which the A bonds are 18.71 bps higher, Baa bonds are 77.21 bps higher, and junk bonds are 466.84 bps higher.

As reported in the second column of Table 6, adding $\gamma$ to the regression does not bring much change to the relative yield spreads across ratings. This is to be expected since $\gamma$ should capture more of a liquidity effect, and less of a fundamental risk effect, which is reflected in the differences in ratings. More importantly, we find that the coefficient on $\gamma$ is 0.4220 with a t-stat of 3.95. This implies that for two bonds in the same rating category, if one bond, presumably less liquid, has a $\gamma$ that is higher than the other by 1, the yield spread of this bond is on average 42.20 bps higher than the other. To put an increase of 1 in $\gamma$ 


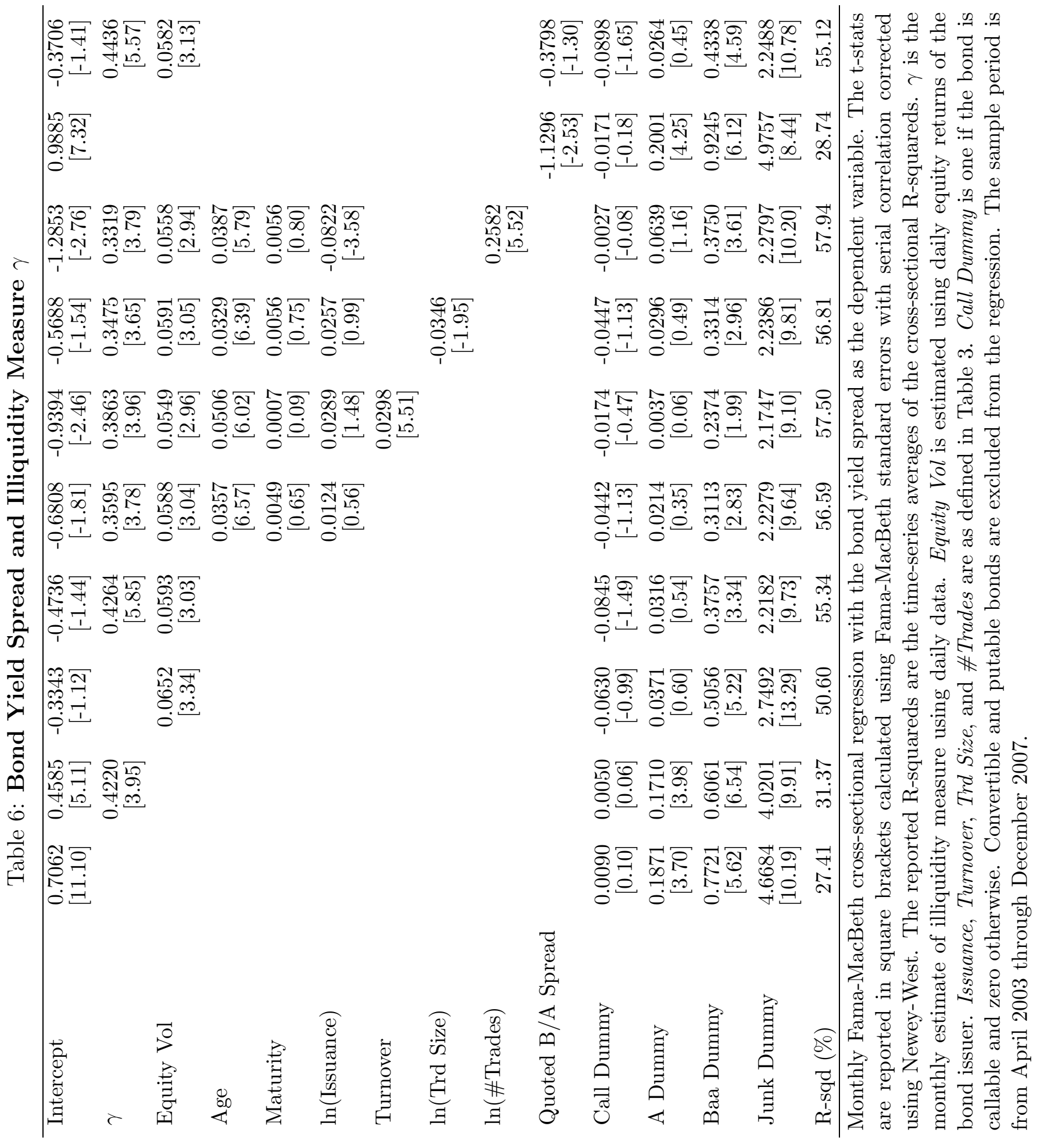


in context, the cross-sectional standard deviation of $\gamma$ is on average 0.9943 in our sample. From this perspective, our illiquidity measure $\gamma$ is economically important in explaining the cross-sectional variation in average bond yields.

To control for the fundamental risk of a bond above and beyond what is captured by the rating dummies, we use equity volatility estimated using daily equity returns of the bond issuer. Effectively, this variable is a combination of the issuer's asset volatility and leverage. We find this variable to be important in explaining yield spreads. As shown in the third column of Table 6, the slope coefficient on equity volatility is 0.0652 with a t-stat of 3.34 . That is, a ten percentage point increase in the equity volatility of a bond issuer is associated with a 65.2 bps increase in the bond yield. (Later in this section when we focus only on investment-grade bonds, we will find that this control becomes less important.) While adding $\gamma$ improves the cross-sectional R-squared from a time-series average of $27.41 \%$ to $31.37 \%$, adding equity volatility improves the R-squared to 50.6\%. Such R-squared's, however, should be interpreted with caution since it is a time-series average of cross-sectional R-squared, and does not take into account the cross-sectional correlations in the regression residuals. By contrast, our reported Fama-MacBeth t-stat's do and both variables are comparable in terms of their statistical significance. It is also interesting to observe that by adding equity volatility, the magnitudes of the rating dummies decrease significantly. This is to be expected since both equity volatility and rating dummies are designed to control for the bond's fundamental risk.

When used simultaneously to explain the cross-sectional variation in bond yield spreads, both $\gamma$ and equity volatility are significant, with the slope coefficients for both remaining more or less the same as before. This implies a limited interaction between the two variables, which is to be expected since the equity volatility is designed to pick up the fundamental information about a bond while $\gamma$ is to capture its liquidity information. Moreover, the statistical significance of our illiquidity measure $\gamma$ increases to a t-stat of 5.85, indicating a closer connection between yield spreads and $\gamma$ after controlling for the fundamental risk.

Adding three bond characteristics - age, maturity and issuance - to compete with $\gamma$, we find that the positive connection between $\gamma$ and average bond yield spreads remains robust. Both bond age and bond issuance are known to be linked to liquidity. ${ }^{16}$ Our results show that bond age remains an important liquidity variable above and beyond our $\gamma$ measure. In particular, a bond that is one year older is associated with an increase of $3.57 \mathrm{bps}$ in average yield spreads.

\footnotetext{
${ }^{16}$ See, for example, Houweling, Mentink, and Vorst (2003) and additional references therein.
} 
Including the bond trading variables reveals that bonds with higher turnover and a large number of trades have higher average yield spreads. The slope coefficients for both variables are statistically significant. If one believes that more frequently traded bonds are more liquid, then this result would be puzzling. It is, however, arguable whether this variable actually captures the liquidity of a bond. We also find that bonds with higher average trade size have lower yield spreads, although the statistical significance is relatively weak (the t-stat is -1.95). This result seems to be consistent with a liquidity explanation. Overall, these variables are important control variables for us, since they are shown in Table 3 to be connected with our illiquidity measure $\gamma$. Our results show that these variables do not have a strong impact on the positive relation between our illiquidity measure $\gamma$ and average yield spreads.

Finally, we examine the relative importance of the quoted bid-ask spreads and our illiquidity measure $\gamma$. As shown in the last two columns of Table 6, the quoted bid-ask spreads are negatively related average yield spreads. Using both the quoted bid-ask spreads and our illiquidity measure $\gamma$, we find a robust result for $\gamma$ and a statistically insignificant result for the quoted bid-ask spread. This aspect of our result is curious since Chen, Lesmond, and Wei (2007) report a positive relation between the quoted bid-ask spreads and yield spreads. We find that this discrepancy is due to the junk bonds in our sample. This is not surprising given that the Phase I and II bonds in TRACE are predominantly investment grades, and the junk bonds covered by TRACE could be an unrepresentative pool. To make sure that our result is not driven by a handful of unrepresentative junk bonds, we next repeat our analysis focusing only on investment grade bonds.

The results for investment-grade bonds only are reported in Table 7 . We find that our illiquidity measure $\gamma$ remains important. Compared with the full sample result, the magnitude of the slope coefficient decreases from 0.4420 to 0.3538 , which is to be expected since having junk bonds in the sample creates a larger spread among yields. But given how large an average spread junk bonds have relative to investment-grade bonds, this reduction in the slope coefficient seems rather small. This new slope coefficient implies that for two investment-grade bonds in the same rating category, if one bond has a $\gamma$ that is higher than the other by 1 , the yield spread of this bond is on average 35.38 bps higher than the other. Within the investment grades, this difference in yields is quite large. Moreover, we also find that the t-stat of the slope coefficient is now 7.02, which is considerably higher than the full sample result. This implies a sharper connection between $\gamma$ and the average yield spreads for investment-grade bonds. 
Table 7: Yield Spread and $\gamma$, for Investment Grades Only

\begin{tabular}{lrrrrrrr}
\hline Intercept & 0.7095 & 0.5172 & 0.5128 & 0.3217 & 0.2631 & 0.5182 & 0.2906 \\
$\gamma$ & {$[9.94]$} & {$[6.43]$} & {$[6.53]$} & {$[3.43]$} & {$[1.28]$} & {$[5.73]$} & {$[2.81]$} \\
& & 0.3548 & & 0.3464 & 0.2271 & & 0.3358 \\
Equity Vol & & {$[7.02]$} & & {$[7.02]$} & {$[4.01]$} & & {$[7.71]$} \\
Age & & & 0.0101 & 0.0107 & 0.0103 & & 0.0107 \\
& & & {$[2.61]$} & {$[2.99]$} & {$[2.74]$} & & {$[2.91]$} \\
Maturity & & & & & 0.0186 & & \\
ln(Issuance) & & & & & {$[3.96]$} & & \\
& & & & & 0.0156 & & \\
Quoted B/A Spread & & & & & -0.0030 & & \\
Call Dummy & & & & & {$[-0.15]$} & & \\
& -0.0070 & -0.0787 & 0.0317 & -0.0514 & -0.0668 & -0.0676 & -0.0633 \\
A Dummy & {$[-0.14]$} & {$[-1.99]$} & {$[0.70]$} & {$[-1.47]$} & {$[-2.49]$} & {$[-1.48]$} & {$[-1.78]$} \\
& 0.1971 & 0.2029 & 0.1586 & 0.1628 & 0.1634 & 0.1923 & 0.1542 \\
Baa Dummy & {$[4.47]$} & {$[5.36]$} & {$[4.07]$} & {$[4.97]$} & {$[5.28]$} & {$[4.73]$} & {$[4.78]$} \\
R-sqd (\%) & 0.7875 & 0.6971 & 0.7059 & 0.6264 & 0.5831 & 0.7386 & 0.6180 \\
\hline
\end{tabular}

Monthly cross-sectional regressions with bond yield spread as the dependent variable. Only investment-grade bonds are included in the regression. The reported estimates are the time-series averages of the cross-sectional regression coefficients. The $t$-stats, reported in square brackets, are calculated using Fama-MacBeth standard errors with serial correlation corrected using Newey-West. The reported R-squareds are the time-series averages of the cross-sectional R-squareds. See Table 6 for definitions of independent variables.

The result for equity volatility is much weaker now that we focus just on the investmentgrade bonds. It also has smaller cross-sectional explanatory power than our $\gamma$ measure, as well as weaker statistical significance. When it is used together with our $\gamma$ measure, there is hardly any change in the slope coefficient for $\gamma$. Adding age, maturity and issuance to the regression, however, the slope coefficient for $\gamma$ is now at 0.2271 with a t-stat of 4.01 . The result is weaker, but remains important both economically and statistically. It is interesting to note that age remains an important variable. Bond maturity becomes important for this sub-sample but not earlier for the full sample.

Turning to the quoted bid-ask spreads, we find a positive and significant relation between the quoted bid-ask spreads and yield spreads, a result that has been documented by Chen, Lesmond, and Wei (2007). Adding our $\gamma$ measure as an additional explanatory variable, however, reduces the economic and statistic significance of the quoted bid-ask spreads in 
explaining the cross-sectional average yield spreads. Specifically, the slope coefficient on the quoted bid-ask spread reduces from 0.7498 to 0.1441 with t-statistics decreasing from 5.12 to 1.92. By contrast, our illiquidity measure $\gamma$ remains important, and the slope coefficient on $\gamma$ is 0.3358 with a t-stat of 7.71 . The relative economic significance of these two competing explanatory variables can be gauged as follows. For the investment grade bonds in our sample with available quoted bid-ask spreads data, the cross-sectional standard deviation of our $\gamma$ measure is on average 0.8397 , and the cross-sectional standard deviation of the quoted bid-ask spreads is on average 0.1686. So a one-standard-deviation difference in $\gamma$ generates a difference of 28.2 bps in average yields, while a one-standard-deviation difference in the quoted bid-ask spread generates a difference of only $2.4 \mathrm{bps}$ in average yields. The fact that our $\gamma$ measure remains more important, both economically and statistically, than the quoted bid-ask spreads in explaining the cross-sectional average yield spreads is another indication that it captures information about illiquidity above and beyond what is contained in the quoted bid-ask spread.

\section{Further Analyses of Illiquidity}

This section provides additional properties of our illiquidity measure. Section 4.1 details the dynamic properties of our illiquidity measure. Section 4.2 documents the asymmetric magnitude of our illiquidity measure conditioning on past price movements. Section 4.3 analyzes the potential profit from exploiting the bond illiquidity. Section 4.4 investigates the differing level of illiquidity by trade size.

\subsection{Dynamic Properties of Illiquidity}

To further examine the dynamic properties of the transitory component in corporate bonds, we measure the autocovariance of price changes that are separated by a few trades or a few days:

$$
\gamma_{\tau}=-\operatorname{Cov}\left(\Delta P_{t}, \Delta P_{t+\tau}\right)
$$

The illiquidity measure we have used so far is simply $\gamma_{1}$. For $\tau>1, \gamma_{\tau}$ measures the extent to which the mean-reversion persists after the initial price reversal at $\tau=1$. In Table 8 , we report the $\gamma_{\tau}$ for $\tau=1,2,3$, using trade-by-trade data. Clearly, the initial bounce back is the strongest while the mean-reversion still persists after skipping a trade. In particular, $\gamma_{2}$ is on average 0.08 with a robust t-stat of 13.81 . At the individual bond level, $67 \%$ of the bonds have a statistically significant $\gamma_{2}$. After skipping two trades, the amount of residual mean-reversion dissipates further in magnitude. The cross-sectional average of $\gamma_{3}$ is only 0.023 , although it is 
still statistically significant with a robust t-stat of 10.70. At the individual bond level, fewer than $12 \%$ of the bonds have a statistically significant $\gamma_{3}$.

Table 8: Dynamics of Illiquidity: $\gamma_{\tau}=-\operatorname{Cov}\left(P_{t}-P_{t-1}, P_{t+\tau}-P_{t+\tau-1}\right)$

\begin{tabular}{|c|c|c|c|c|c|c|c|}
\hline & & 2003 & 2004 & 2005 & 2006 & 2007 & Full \\
\hline \multirow[t]{4}{*}{$\tau=1$} & Mean $\gamma$ & 0.6546 & 0.6714 & 0.5717 & 0.4677 & 0.4976 & 0.5814 \\
\hline & Median $\gamma$ & 0.4520 & 0.3928 & 0.3170 & 0.2588 & 0.2830 & 0.3598 \\
\hline & Per t-stat $\geq 1.96$ & 99.74 & 97.53 & 99.31 & 98.69 & 97.45 & 100.00 \\
\hline & Robust t-stat & 16.87 & 16.01 & 19.10 & 20.56 & 19.51 & 22.23 \\
\hline \multirow[t]{4}{*}{$\tau=2$} & Mean $\gamma$ & 0.0808 & 0.0679 & 0.0824 & 0.0598 & 0.1012 & 0.0805 \\
\hline & Median $\gamma$ & 0.0373 & 0.0236 & 0.0320 & 0.0261 & 0.0554 & 0.0395 \\
\hline & Per t-stat $\geq 1.96$ & 27.87 & 19.77 & 38.03 & 39.78 & 52.87 & 67.41 \\
\hline & Robust t-stat & 10.24 & 7.42 & 13.22 & 11.02 & 13.97 & 13.81 \\
\hline \multirow[t]{4}{*}{$\tau=3$} & Mean $\gamma$ & 0.0105 & 0.0239 & 0.0221 & 0.0280 & 0.0277 & 0.0233 \\
\hline & Median $\gamma$ & 0.0054 & 0.0048 & 0.0049 & 0.0049 & 0.0067 & 0.0065 \\
\hline & Per t-stat $\geq 1.96$ & 5.16 & 5.52 & 6.27 & 8.68 & 6.69 & 11.93 \\
\hline & Robust t-stat & 2.71 & 4.30 & 7.87 & 7.26 & 7.72 & 10.70 \\
\hline
\end{tabular}

For each bond, its $\gamma_{\tau}, \tau=1,2,3$, is calculated using trade-by-trade data. Per t-stat $\geq 1.96$ reports the percentage of bond with statistically significant $\gamma$. Robust t-stat is a test on the cross-sectional mean of $\gamma$ with standard errors corrected for cross-sectional and time-series correlations.

The fact that the mean-reversion persists for a few trades before fulling dissipating implies that autocovariance at the daily level is stronger than at the trade-by-trade level as it captures the effect cumulatively, as shown in Table 2. At the daily level, however, the mean-reversion dissipates rather quickly, with an insignificant $\gamma_{2}$ and $\gamma_{3}$. For brevity, we omit these results.

\subsection{Asymmetry in Price Reversals}

One interesting question regarding the mean-reversion captured in our main result is whether or not the magnitude of mean-reversion is symmetric in the sign of the initial price change. Specifically, with $\Delta P$ properly demeaned, let $\gamma^{-}=E\left(\Delta P_{t} \Delta P_{t+1} \mid \Delta P_{t}<0\right)$ be a measure of mean-reversion conditioning on an initial price change that is negative, and let $\gamma^{+}$be the counterpart conditioning on a positive price change. In a simple theory of liquidity based on costly market participation, Huang and Wang (2007) show that the bounce-back effect is more severe conditioning on an initial price movement that is negative, predicting a positive difference between $\gamma^{-}$and $\gamma^{+}$.

We test this hypothesis in Table 9, which shows that indeed there is a positive difference between $\gamma^{-}$and $\gamma^{+}$. Using trade-by-trade data, the cross-sectional average of $\gamma^{-}-\gamma^{+}$is 0.0802 
Table 9: Asymmetry in $\gamma$

\begin{tabular}{llrrrrrr}
\hline \multicolumn{7}{c}{ Panel A: Using trade-by-trade data } \\
& 2003 & 2004 & 2005 & 2006 & 2007 & Full \\
\hline$\tau=1$ & Mean & 0.1442 & 0.0674 & 0.0120 & 0.0455 & 0.0689 & 0.0802 \\
& Median & 0.1347 & 0.0292 & -0.0030 & 0.0257 & 0.0574 & 0.0347 \\
& CS t-stat & 7.92 & 3.71 & 0.92 & 3.93 & 5.87 & 5.98 \\
& Robust t-stat & 6.53 & 3.44 & 0.88 & 3.71 & 5.55 & 5.59 \\
\hline$\tau=2$ & Mean & 0.0351 & 0.0328 & 0.0444 & 0.0411 & 0.0508 & 0.0457 \\
& Median & 0.0146 & 0.0077 & 0.0104 & 0.0160 & 0.0228 & 0.0145 \\
& CS t-stat & 5.01 & 4.34 & 9.47 & 9.63 & 8.14 & 9.29 \\
& Robust t-stat & 4.94 & 4.11 & 8.20 & 8.17 & 7.61 & 8.59 \\
\hline
\end{tabular}

Panel B: Using daily data

\begin{tabular}{llrrrrrr} 
& & 2003 & 2004 & 2005 & 2006 & 2007 & Full \\
\hline$\tau=1$ & Mean & 0.2759 & 0.1628 & 0.1090 & 0.1232 & 0.1529 & 0.1753 \\
& Median & 0.1948 & 0.0449 & 0.0173 & 0.0469 & 0.0952 & 0.0708 \\
& CS t-stat & 9.92 & 5.50 & 4.82 & 5.77 & 6.22 & 9.63 \\
& Robust t-stat & 8.92 & 4.85 & 4.40 & 5.01 & 5.65 & 8.89 \\
\hline$\tau=2$ & Mean & -0.0036 & 0.0026 & 0.0091 & -0.0021 & 0.0154 & 0.0059 \\
& Median & 0.0003 & -0.0011 & -0.0003 & 0.0012 & 0.0012 & 0.0009 \\
& CS t-stat & -0.33 & 0.18 & 1.01 & -0.26 & 1.26 & 0.96 \\
& Robust t-stat & -0.28 & 0.18 & 0.86 & -0.24 & 1.07 & 0.87 \\
\hline
\end{tabular}

Asymmetry in $\gamma$ is measured by the difference between $\gamma^{-}$and $\gamma^{+}$, where $\gamma^{-}=$ $E\left(\Delta P_{t+1} \Delta P_{t} \mid \Delta P_{t}<0\right)$, with $\Delta P$ properly demeaned, measures the price reversal conditioning on a negative price movement. Likewise, $\gamma^{+}$measures the price reversal conditioning on a positive price movement. Robust t-stat is a pooled test on the mean of $\gamma^{-}-\gamma^{+}$with standard errors clustered by bond and day. CS t-stat is the cross-sectional t-stat.

with a robust t-stat of 5.59. Skipping a trade, the asymmetry in $\gamma_{2}$ is on average 0.0457 with a robust t-stat of 8.59. Compared with how $\gamma_{\tau}$ dissipates across $\tau$, this measure of asymmetry does not exhibit the same dissipating pattern. In fact, in the later sample period, the level of asymmetry for $\tau=2$ is almost as important for the first-order mean-reversion, with an even higher statistical significance. Using daily data, the asymmetry is stronger, incorporating the cumulative effect from the transaction level. The cross-sectional average of $\gamma^{-}-\gamma^{+}$is 0.18 , which is close to $20 \%$ of the observed level of mean reversion. Skipping a day, however, produces no evidence of asymmetry, which is expected since there is very little evidence of mean-reversion at this level in the first place. 


\subsection{Profiting from Illiquidity}

Given the large magnitude of negative autocovariance documented in this section, it is natural to ask whether or not there is a feasible trading strategy to profit from this severe illiquidity in corporate bonds. To address this question, we devise the simple contrarian strategy that takes a long position in a bond when its price moves downward by more than a threshold, and takes a short position when the price moves upward by more than the threshold. This strategy entails supplying liquidity in the market. For comparison, we consider two values for the threshold, zero and one dollar. Given our asymmetry result for $\gamma$, as well as the differing implications of taking long or short positions in corporate bonds, we also report the profits for the short and long positions separately. Table 10 reports the trading profits using tradeby-trade data. For the full sample and for the trading strategy with a zero threshold in price changes, the average daily profit per bond is $\$ 2.88$ for a $\$ 100$ notional position. The robust t-stat (clustered by bond and day) for this profit is 16.90. On average, the bond is traded 7.53 times a day. Separating the signal to buy and sell separately, the buy signal yields a slightly higher profit, which is consistent with our asymmetry result on price reversals.

It is important to note that only the market makers can trade at the price for which the signal is observed. A realistic trading strategy is therefore to skip a trade after the signal is observed and then buy and sell accordingly. As shown in the right panel of Table 10, the average profit of this trading strategy is markedly lower. For the full sample and for the trading strategy with the threshold of $\$ 1$, the average profit is 25 cents on a $\$ 100$ notional, and it carries a robust t-stat of 16.12. The buy signal generates a profit that is twice as large as the sell signal, consistent with the fact that the asymmetry remains important after skipping a trade.

\subsection{Trade Size and Illiquidity}

Since our illiquidity measure is based on transaction prices, a natural question is how it is related to the sizes of these transactions. In particular, are reversals in price changes stronger for trades of larger or smaller sizes? In order to answer this question, we consider the autocovariance of price changes conditional on different trade sizes.

For a change in price $P_{t}-P_{t-1}$, let $V_{t}$ denote the size of the trade associated with price $P_{t}$. The autocovariance of price changes conditional on trade size being in a particular range, say, $R$, is defined as

$$
\operatorname{Cov}\left(P_{t}-P_{t-1}, P_{t+1}-P_{t}, \mid V_{t} \in R\right),
$$




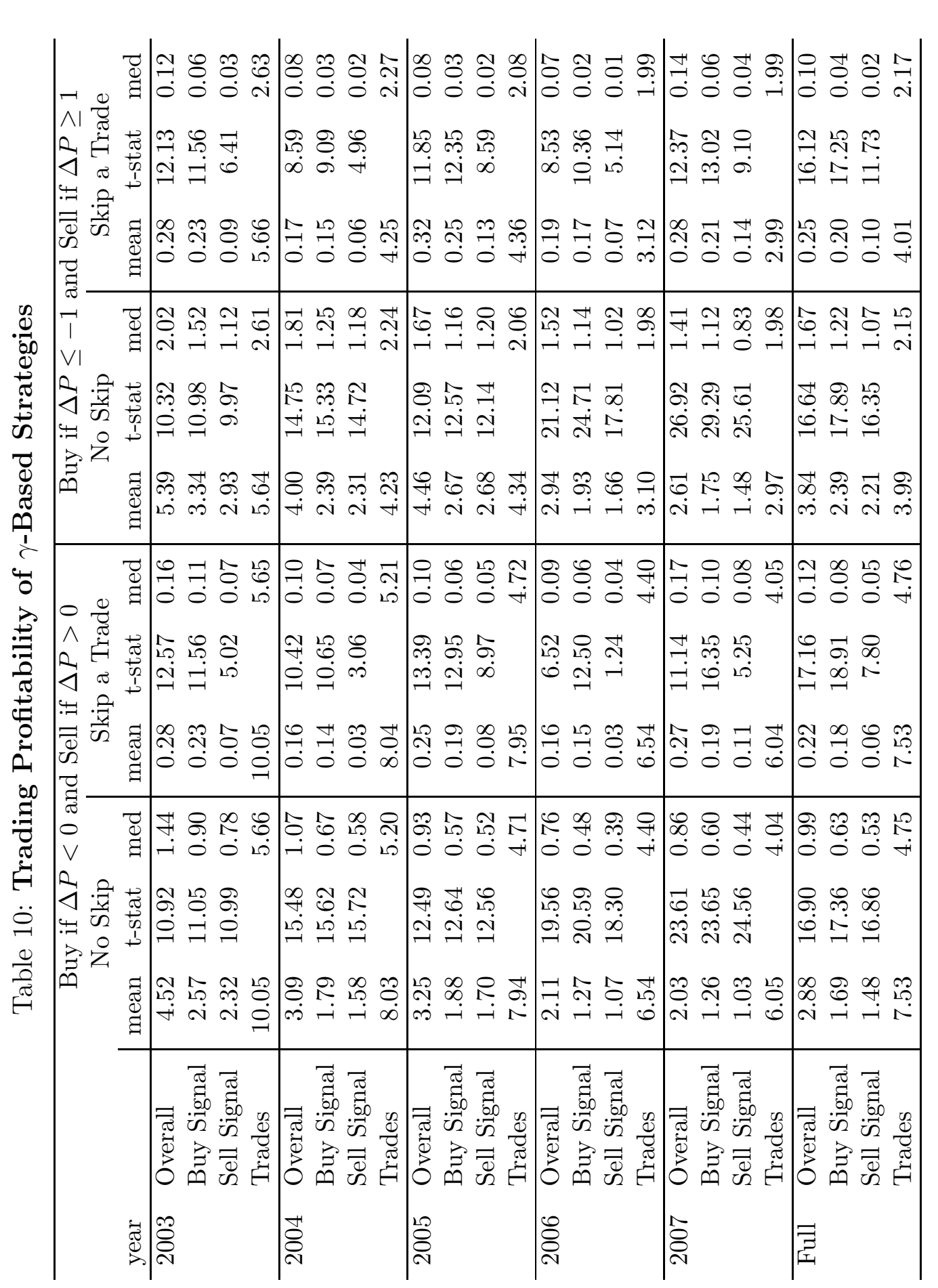

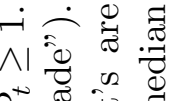

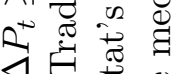

व 莲完

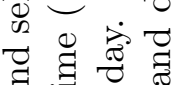
สี ᄀ疋

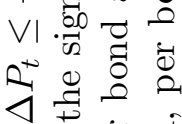

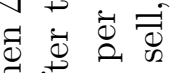

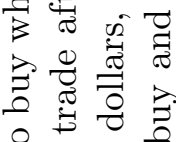
$\begin{array}{ccc}0 & 0 \\ 0 & 0 & 0 \\ 0 & 0\end{array}$

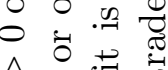

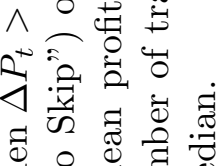

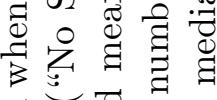
च త్ర హె $\checkmark \cdot 0$.010

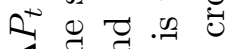
$\checkmark \nsubseteq$ क्ष 苞芯芯 氠所 \#

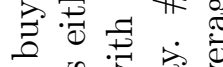
$\circ$ 击完 .

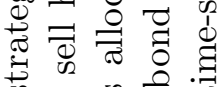
的工 車司焉

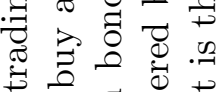

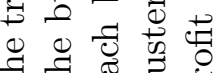

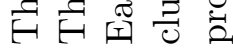


where six brackets of trade sizes are considered in our estimation: $(\$ 0, \$ 5 \mathrm{~K}],(\$ 5 \mathrm{~K}, \$ 15 \mathrm{~K}]$, $(\$ 15 \mathrm{~K}, \$ 25 \mathrm{~K}],(\$ 25 \mathrm{~K}, \$ 75 \mathrm{~K}],(\$ 75 \mathrm{~K}, \$ 500 \mathrm{~K}]$, and $(\$ 500 \mathrm{~K}, \infty)$, respectively. Our choice of the number of brackets and their respective cutoffs is influenced by the sample distribution of trade sizes. In particular, to facilitate the estimation of $\gamma$ conditional on trade size, we need to have enough transactions within each bracket for each bond to obtain a reliable conditional $\gamma$.

For the same reason, we construct our conditional $\gamma$ using trade-by-trade data. Otherwise, the data would be cut too thin at the daily level to provide reliable estimates of conditional $\gamma$. For each bond, we categorize transactions by their time-t trade sizes into their respective bracket $s$, with $s=1,2, \ldots, 6$, and collect the corresponding pairs of price changes, $P_{t}-P_{t-1}$ and $P_{t+1}-P_{t}$. Grouping such pairs of prices changes for each size bracket $s$ and for each bond, we can estimate the autocovariance of the price changes, the negative of which is our conditional $\gamma(s)$.

Equipped with the conditional $\gamma$, we can now explore the link between trade size and illiquidity. In particular, does $\gamma(s)$ vary with $s$ and how? We answer this question by first controlling for the overall liquidity of the bond. This control is important as we find in Section 3.2 the average trade size of a bond is an important determinant of the cross-sectional variation of $\gamma$. So we first sort all bonds by their unconditional $\gamma$ into quintiles and then examine the connection between $\gamma(s)$ and $s$ within each quintile.

As shown in Panel A of Table 11, for each $\gamma$ quintile, there is a pattern of decreasing conditional $\gamma$ with increasing trade size and the relation is monotonic for all $\gamma$ quintiles. For example, quintile 1 consists of bonds with the highest $\gamma$ and therefore the least liquid in our sample. The mean $\gamma$ is 2.1129 for trade-size bracket 1 (less than $\$ 5 \mathrm{~K}$ ) but it decreases to 0.6171 for trade-size bracket 6 (greater than $\$ 500 \mathrm{~K}$ ). The mean difference in $\gamma$ between the trade-size bracket 1 and 6 is 1.4292 and has a robust t-stat of 10.72. Likewise, for quintile 5, which consists of bonds with the lowest $\gamma$ measure and therefore are the most liquid, the same pattern emerges. The average value of $\gamma$ is 0.2172 for the smallest trades and then decreases monotonically to 0.0202 for the largest trades. The difference between the two is 0.1976 , with a robust t-stat of 9.39, indicating that the conditional $\gamma$ between small and large size trades remains significant even for the most liquid bonds. To check the potential impact of outliers, we also report the median $\gamma$ for different trade sizes. Although the magnitudes are slightly smaller, the general pattern remains the same.

We next examine the connection between trade sizes and conditional $\gamma_{\tau}$ for $\tau=2$. As introduced in equation (3), we use $\gamma_{2}$ to estimate the persistence of mean-reversion using price 
Table 11: Variation of $\gamma$ with Trade Size

\begin{tabular}{|c|c|c|c|c|c|c|c|c|}
\hline \multicolumn{9}{|c|}{ Panel A: Lag=1 } \\
\hline \multirow{4}{*}{$\begin{array}{l}\gamma \text { Quint } \\
1\end{array}$} & trade size $=$ & 1 & 2 & 3 & 4 & 5 & 6 & $1-6$ \\
\hline & Mean & 2.1129 & 1.6404 & 1.4614 & 1.2703 & 0.8477 & 0.6171 & 1.4292 \\
\hline & Median & 1.8844 & 1.4902 & 1.3459 & 1.2088 & 0.7812 & 0.4835 & 1.3132 \\
\hline & Robust t-stat & 13.55 & 10.09 & 9.18 & 9.20 & 8.44 & 6.27 & 10.72 \\
\hline \multirow[t]{3}{*}{2} & Mean & 1.0974 & 0.9468 & 0.8440 & 0.6748 & 0.3330 & 0.1906 & 0.9064 \\
\hline & Median & 0.9990 & 0.8773 & 0.7962 & 0.6274 & 0.3138 & 0.1716 & 0.8272 \\
\hline & Robust t-stat & 10.49 & 9.42 & 9.53 & 10.44 & 13.35 & 11.54 & 8.92 \\
\hline \multirow[t]{3}{*}{3} & Mean & 0.6282 & 0.5545 & 0.4882 & 0.3544 & 0.1726 & 0.0804 & 0.5493 \\
\hline & Median & 0.5423 & 0.4989 & 0.4577 & 0.3327 & 0.1646 & 0.0723 & 0.4656 \\
\hline & Robust t-stat & 8.43 & 12.98 & 13.46 & 14.00 & 15.71 & 12.15 & 7.49 \\
\hline \multirow[t]{3}{*}{4} & Mean & 0.3881 & 0.3217 & 0.2662 & 0.1814 & 0.0971 & 0.0424 & 0.3472 \\
\hline & Median & 0.3242 & 0.2831 & 0.2308 & 0.1673 & 0.0893 & 0.0394 & 0.2879 \\
\hline & Robust t-stat & 8.25 & 12.77 & 12.98 & 14.47 & 16.70 & 12.52 & 7.46 \\
\hline \multirow[t]{3}{*}{5} & Mean & 0.2172 & 0.1652 & 0.1327 & 0.0895 & 0.0469 & 0.0202 & 0.1976 \\
\hline & Median & 0.1957 & 0.1490 & 0.1167 & 0.0833 & 0.0430 & 0.0175 & 0.1755 \\
\hline & Robust t-stat & 10.19 & 13.72 & 11.73 & 15.34 & 17.53 & 15.35 & 9.39 \\
\hline \multicolumn{9}{|c|}{ Panel B: Lag $=2$} \\
\hline \multirow{4}{*}{$\begin{array}{l}\gamma \text { Quint } \\
1\end{array}$} & trade size $=$ & 1 & 2 & 3 & 4 & 5 & 6 & $1-6$ \\
\hline & Mean & 0.3652 & 0.1774 & 0.1784 & 0.1622 & 0.1164 & 0.0936 & 0.3497 \\
\hline & Median & 0.3418 & 0.1995 & 0.1754 & 0.1341 & 0.1016 & 0.0495 & 0.2688 \\
\hline & Robust t-stat & 7.57 & 6.72 & 6.19 & 6.11 & 4.50 & 3.52 & 7.70 \\
\hline \multirow[t]{3}{*}{2} & Mean & 0.1997 & 0.1416 & 0.1043 & 0.0842 & 0.0566 & 0.0195 & 0.1806 \\
\hline & Median & 0.1503 & 0.0927 & 0.0865 & 0.0644 & 0.0410 & 0.0155 & 0.1275 \\
\hline & Robust t-stat & 8.37 & 6.06 & 7.49 & 7.12 & 8.19 & 3.84 & 7.70 \\
\hline \multirow[t]{3}{*}{3} & Mean & 0.0961 & 0.0721 & 0.0509 & 0.0420 & 0.0226 & 0.0086 & 0.0878 \\
\hline & Median & 0.0782 & 0.0542 & 0.0358 & 0.0285 & 0.0183 & 0.0060 & 0.0702 \\
\hline & Robust t-stat & 7.32 & 7.92 & 7.39 & 5.78 & 6.45 & 2.92 & 6.66 \\
\hline \multirow[t]{3}{*}{4} & Mean & 0.0647 & 0.0484 & 0.0341 & 0.0257 & 0.0083 & 0.0052 & 0.0599 \\
\hline & Median & 0.0474 & 0.0318 & 0.0191 & 0.0160 & 0.0066 & 0.0027 & 0.0432 \\
\hline & Robust t-stat & 6.75 & 7.88 & 6.88 & 8.08 & 5.50 & 2.85 & 6.20 \\
\hline \multirow[t]{3}{*}{5} & Mean & 0.0317 & 0.0219 & 0.0126 & 0.0122 & 0.0065 & 0.0016 & 0.0301 \\
\hline & Median & 0.0254 & 0.0146 & 0.0103 & 0.0084 & 0.0043 & 0.0014 & 0.0231 \\
\hline & Robust t-stat & 7.48 & 7.11 & 4.87 & 5.77 & 6.91 & 2.21 & 7.05 \\
\hline
\end{tabular}

Trade size is categorized into 6 groups with cutoffs of $\$ 5 \mathrm{~K}, \$ 15 \mathrm{~K}, \$ 25 \mathrm{~K}, \$ 75 \mathrm{~K}$, and $\$ 500 \mathrm{~K}$. For $\operatorname{Lag}=1, \gamma=-\operatorname{Cov}\left(P_{t}-P_{t-1}, P_{t+1}-P_{t}\right)$, and for $\operatorname{Lag}=2, \gamma=-\operatorname{Cov}\left(P_{t}-P_{t-1}, P_{t+2}-\right.$ $\left.P_{t+1}\right)$. In both cases, $\gamma$ is calculated conditioning on the trade size associated with $P_{t}$. Bonds are sorted by their "unconditional" $\gamma$ into quintiles, and the variation of $\gamma$ by trade size is reported for each quintile group. The trade-by-trade data is used in the calculation. For the daily data, the results are similar but stronger for $\mathrm{Lag}=1$, and weaker and statistically insignificant for $\mathrm{Lag}=2$. 
changes after skipping a trade. The conditional version of $\gamma_{2}$ can be calculated as the negative of $\operatorname{Cov}\left(P_{t}-P_{t-1}, P_{t+2}-P_{t+1} \mid V_{t} \in\right.$ bracket $\left.s\right)$, for $s=1,2, \ldots, 6$. The empirical estimates are reported in Panel B of Table 11. Again, we see a quite robust pattern of decreasing $\gamma_{2}(s)$ with increasing trade size bracket $s$, indicating that even skipping a trade, there are weaker reversals after large-size trades and stronger reversals after small-size trades.

Overall, our results demonstrate a clear negative relation between trade sizes and our illiquidity measure. The interpretation of this result, however, requires caution. It would be simplistic to infer from this pattern that larger trades face less illiquidity or have less impact on prices. It is important to realize that both trades sizes and prices are endogenous variables. Their relation arises from an equilibrium outcome in which traders optimally choose their trading strategies, taking into account the price dynamics and the impact of their trades. For example, when liquidity varies over time, traders may optimally break up their trades when liquidity is low. Consequently, during less liquid times, we see more small trades and a larger illiquidity measure $\gamma$.

\section{$5 \quad$ Illiquidity and Bid-Ask Spread}

It is well known that the bid-ask spread can lead to negative autocovariance in price changes. For example, using a simple specification, Roll (1984) shows that when transactions prices bounce between bid and ask prices, depending on whether they are sell or buy orders from customers, their changes exhibit negative autocovariance even when the "underlying value" follows a random walk. Thus, it is important to ask whether or not the negative autocovariances documented in this paper are simply a reflection of bid-ask bounce. Using quoted bid-ask spreads, we show in Table 2 that the associated bid-ask bounce can only generate a tiny fraction of the empirically observed autocovariance in corporate bonds. Quoted spreads, however, are mostly indicative rather than binding. Moreover, the structure of the corporate bond market is mostly over-the-counter, making it even more difficult to estimate the actual bid-ask spreads. ${ }^{17}$ Thus, a direct examination of how bid-ask spreads contribute to our illiquidity measure $\gamma$ is challenging.

We can, however, address this question to certain extent by taking advantage of the results by Edwards, Harris, and Piwowar (2007) (EHP hereafter). Using a more detailed version of the

\footnotetext{
${ }^{17}$ The corporate bond market actually involves different trading platforms, which provide liquidity to different clienteles. In such a market, a single bid-ask spread can be too simplistic in capturing the actual spreads in the market.
} 
TRACE data that includes the side on which the dealer participated, they provide estimates of effective bid-ask spreads for corporate bonds. To examine the extent to which our illiquidity measure $\gamma$ can be explained by the estimated bid-ask spread, we use our illiquidity measure $\gamma$ to compute the implied bid-ask spreads, and compare them with the estimated bid-ask spreads reported by EHP. The actual comparison will not be exact, since our sample of bonds is different from theirs. Later in the section, we will discuss how this could affect our analysis.

It is first instructive to understand the theoretical underpinning of how our estimate of $\gamma$ relates to the estimate of bid-ask spreads in EHP. In the Roll (1984) model, the transaction price $P_{t}$ takes the form of equation (1), in which $P$ is the sum of the fundamental value and a transitory component. Moreover, the transitory component equals to $\frac{1}{2} S q_{t}$ in the Roll model, with $S$ being the bid-ask spread and $q_{t}$ indicating the direction of trade. Specifically, $q$ is +1 if the transaction is buyer initiated and -1 if it is seller initiated, assuming that the dealer takes the other side. More specifically, in the Roll model, we have

$$
P_{t}=F_{t}+\frac{1}{2} S q_{t}
$$

If we further assume that $q_{t}$ is i.i.d. over time, the autocovariance in price change then becomes $-(S / 2)^{2}$, or $\gamma=(S / 2)^{2}$. Conversely, we have

$$
S_{\text {Roll }}=2 \sqrt{\gamma}
$$

where we call $S_{\text {Roll }}$ the implied bid-ask spread.

EHP use an enriched Roll model, which allows the spreads to depend on trade sizes. In particular, they assume

$$
P_{t}=F_{t}+\frac{1}{2} S\left(V_{t}\right) q_{t}
$$

where $V_{t}$ is the size of the trade at time $t .{ }^{18}$ Since the dataset used by EHP also contains information about $q_{t}$, they directly estimate the first difference of equation (7), assuming a factor model for the increments of $F_{t}$.

Table 12 reproduces the results of EHP, who estimate percentage bid-ask spreads for average trade sizes of $\$ 5 \mathrm{~K}, \$ 10 \mathrm{~K}, \$ 20 \mathrm{~K}, \$ 50 \mathrm{~K}, \$ 100 \mathrm{~K}, \$ 200 \mathrm{~K}, \$ 500 \mathrm{~K}$ and $\$ 1 \mathrm{M}$. The crosssectional medians of the percentage bid-ask spreads are 1.20\%, 1.12\%, 96 bps, 66 bps, 48 bps, 34 bps, 20 bps and 12 bps, respectively. To compare with their results, we form trade

\footnotetext{
${ }^{18}$ The model EHP use has an additional feature. It distinguishes customer-dealer trades from dealer-dealer trades. The spread they estimate is for the customer-dealer trades. Thus, in (7), we simply do not identify dealer-dealer trades. This decreases our estimate of $\gamma$ relative to EHP since we are including inter-dealer trades which have a smaller spread than customer-dealer trades.
} 
Table 12: Implied and Estimated Bid-Ask Spreads

\begin{tabular}{l|rrr|rrr|rrr}
\hline & \multicolumn{3}{|c|}{ Full Sample Period } & \multicolumn{5}{|c}{ EHP Subperiod } \\
& \multicolumn{2}{|c|}{$\gamma$-Implied } & \multicolumn{3}{|c}{$\gamma$-Implied } & \multicolumn{3}{c}{ EHP Estimated } \\
trade size & \#bonds & mean & med & \#bonds & mean & med & EHP size & mean & med \\
\hline$\leq 7,500$ & 1,201 & 2.05 & 1.76 & 956 & 2.06 & 1.81 & $5 \mathrm{~K}$ & 1.50 & 1.20 \\
$(7500,15 \mathrm{~K}]$ & 1,209 & 1.82 & 1.61 & 1,069 & 1.98 & 1.79 & $10 \mathrm{~K}$ & 1.42 & 1.12 \\
$(15 \mathrm{~K}, 35 \mathrm{~K}]$ & 1,211 & 1.69 & 1.41 & 1,067 & 1.81 & 1.60 & $20 \mathrm{~K}$ & 1.24 & 0.96 \\
$(35 \mathrm{~K}, 75 \mathrm{~K}]$ & 1,210 & 1.43 & 1.15 & 925 & 1.39 & 1.20 & $50 \mathrm{~K}$ & 0.92 & 0.66 \\
$(75 \mathrm{~K}, 150 \mathrm{~K}]$ & 1,183 & 1.13 & 0.90 & 831 & 1.00 & 0.89 & $100 \mathrm{~K}$ & 0.68 & 0.48 \\
$(150 \mathrm{~K}, 350 \mathrm{~K}]$ & 1,088 & 0.82 & 0.70 & 701 & 0.67 & 0.66 & $200 \mathrm{~K}$ & 0.48 & 0.34 \\
$(350 \mathrm{~K}, 750 \mathrm{~K}]$ & 1,126 & 0.69 & 0.59 & 801 & 0.60 & 0.57 & $500 \mathrm{~K}$ & 0.28 & 0.20 \\
$>750 \mathrm{~K}$ & 1,144 & 0.64 & 0.55 & 982 & 0.52 & 0.54 & $1,000 \mathrm{~K}$ & 0.18 & 0.12 \\
\hline
\end{tabular}

The bid-ask spreads are calculated as a percentage of the market value of the bond and are reported in percentages. The EHP bid-ask spread estimates are from Table 4 of Edwards, Harris, and Piwowar (2007), and the EHP subperiod is Jan. 2003 to Jan. 2005. Our bid-ask spreads are obtained using Roll's measure: $2 \sqrt{\gamma}$ divided by the average market value of the bond. The sample of bonds differs from that in EHP, and our selection criteria bias us toward more liquid bonds with smaller bid-ask spreads.

size brackets that center around their reported trade sizes. For example, to compare with their trade size $\$ 10 \mathrm{~K}$, we calculate our illiquidity measure $\gamma$ conditional on trade sizes falling between $\$ 7.5 \mathrm{~K}$ and $\$ 15 \mathrm{~K}$, and then calculate the implied bid-ask spread. Using the average price for the respective bond, we further convert the spread to percentage spread so as to compare with the EHP result. The results are reported in Table 12, where to correct for the difference in our respective sample periods, we also report our implied bid-ask spreads for the period used by EHP. For the EHP sample period, the cross-sectional medians of our implied percentage bid-ask spreads are 1.81\%, 1.79\%, 1.60\%, 1.20\%, 89 bps, 66 bps, 57 bps, and 54 bps, respectively. As we move on to compare our median estimates to those in EHP, it should be mentioned that this is a simple comparison by magnitudes, not a formal statistical test.

Overall, our implied spreads are much higher than those estimated by EHP. For small trades, our median estimates of implied spreads are over $50 \%$ higher than those by EHP. Moving to larger trades, the difference becomes even more substantial. Our median estimates are close to doubling theirs for the average sizes of $\$ 100 \mathrm{~K}$ and $\$ 200 \mathrm{~K}$, close to tripling theirs for the average size of $\$ 500 \mathrm{~K}$, and more than quadrupling theirs for the average size of $\$ 1,000 \mathrm{~K}$. In fact, our estimates are biased downward for the trade size group around $\$ 1,000 \mathrm{~K}$, since our estimated bid-ask spreads include all trade sizes above $\$ 750 \mathrm{~K}$, including trade sizes of $\$ 2 \mathrm{M}$, $\$ 5 \mathrm{M}$, and $\$ 10 \mathrm{M}$, whose median bid-ask spreads are estimated by EHP to be 6 bps, 2 bps, and 2 bps, respectively. We have to group such trade sizes because in the publicly available 
TRACE data, the reported trade size is truncated at $\$ 1 \mathrm{M}$ for speculative grade bonds and at $\$ 5 \mathrm{M}$ for investment grade bonds.

In addition to differing in sample periods, which is easy to correct, our sample is also different from that used in EHP in the composition of the bonds that are used to estimate the bid-ask spreads. In particular, our selection criteria bias our sample towards highly liquid bonds. For example, to be included in our sample, the bond has to trade at least $75 \%$ of business days, while the median frequency of days with a trade is only $48 \%$ for the bonds used in EHP. The median average trade sizes is $\$ 467 \mathrm{~K}$ in 2003 and $\$ 405 \mathrm{~K}$ in 2004 for the bonds used in our sample, compared with $\$ 240 \mathrm{~K}$ for the bonds used in EHP; the median average number of trades per month is 148 in 2003 and 118 in 2004 for the bonds in our sample, while the median average number of trades per day is 1.1 for the bonds used in EHP. Given that more liquid bonds typically have smaller bid-ask spreads, the difference between our implied bid-ask spreads and EHP's estimates would have been even more drastic had we been able to match our sample of bonds to theirs. It is therefore our conclusion that the negative autocovariance in price changes observed in the bond market is much more substantial than merely the bid-ask effect. And our measure of illiquidity captures more broadly the impact of illiquidity in the market.

Finally, one might be curious as to what is the exact mechanism that drives our estimates apart from those by EHP. After all, within the Roll model as specified in equation (6), our estimates should be identical to theirs. The fact that our results are so different is a clear rejection of the model. Under the Roll model, using equation (5) to identify bid-ask spread $S$ implies regressing $\Delta P_{t}$ on $\Delta q_{t}$. But using our model specified in equation (1) as a reference, it is possible that the transitory component $u_{t}$ does not take the simple form of $\frac{1}{2} S q_{t}$. More specifically, the residual of this regression of $\Delta P_{t}$ on $\Delta q_{t}$ might still exhibit a high degree of negative autocovariance, simply because $u_{t}$ is not fully captured by $\frac{1}{2} S q_{t}$. If that is true, then our measure of illiquidity captures the transitory component more completely: both the bid-ask bounce associated with $\frac{1}{2} S q_{t}$ and the additional mean-reversion that is not related to bid-ask bounce. Using a dataset from Market Access, we are able to confirm this conjecture on the trades going through its trading platform.

\section{Conclusions}

The main objective of our paper is to gauge the level of illiquidity in the corporate bond market and to examine its key properties and implications. Using a theoretically motivated 
measure of illiquidity, i.e., the amount of price reversals as captured by the negative of autocovariance of prices changes, we show that this illiquidity measure is both statistically and economically significant for a broad cross-section of corporate bonds examined in this paper. We demonstrate that the magnitude of the reversals is beyond what can be explained by bidask bounce. We also show that the reversals exhibit significant asymmetry: price reversals are on average stronger after a price reduction than a price increase. Simple contrarian strategies that take advantage of these price reversals yield substantial profits.

We find that a bond's illiquidity is related to several bond characteristics. In particular, illiquidity increases with a bond's age and maturity, but decreases with its rating and issue size. While a bond's illiquidity shows little relation with its market risk exposures, as measured by its beta with respect to the stock and bond market indices, it is positively related to its idiosyncratic return volatility. We also find that price reversals are inversely related to trade sizes. That is, prices changes accompanied by small trades exhibit stronger reversals than those accompanied by large trades.

Furthermore, the illiquidity of individual bonds fluctuates substantially over time. More interestingly, these time fluctuations display important commonalities. For example, the average illiquidity over all bonds, which represents a market-wide illiquidity, increases sharply during the periods of market turmoil such as the downgrade of Ford and GM to junk status around May of 2005 and the sub-prime market crisis starting in August 2007. Exploring the relation between changes in the market-wide illiquidity and other market variables, we find that changes in illiquidity are positively related to changes in VIX while negatively related to lagged returns of the aggregate stock market. Surprisingly, there is only a weak relation with changes in the default spread and lagged returns of the aggregate bond market. Using principal component analysis, we further show that changes in illiquidity of individual bonds share four principal components, which explain over $80 \%$ of the variation in the liquidity of bond portfolios sorted on their characteristics.

We also find important pricing implications associated with bond illiquidity. Our result shows that for two bonds in the same rating category, a one-standard-deviation difference in their illiquidity measure would set their yield spreads apart by over $40 \mathrm{bps}$. This result remains robust in magnitude and statistical significance, after controlling for bond fundamental information and bond characteristics including those commonly related to bond liquidity.

Our results raise several questions concerning the liquidity of corporate bonds. First, what are the underlying factors giving rise to the high level of illiquidity? This question is particu- 
larly pressing when we contrast the magnitude of our illiquidity measure in the corporate bond market against that in the equity market. Second, what causes the fluctuations in the overall level of illiquidity in the market? Are these fluctuations merely another manifestation of more fundamental risks or a reflection of new sources of risks such as a liquidity risk? Third, does the high level of illiquidity for the corporate bonds indicate any inefficiencies in the market? If so, what would be the policy remedies? We leave these questions for future work. 


\section{References}

Bao, J. and J. Pan (2008). Excess Volatiity of Corporate Bonds. Working Paper, MIT Sloan.

Bessembinder, H., W. Maxwell, and K. Venkataraman (2006). Optimal Market Transparency: Evidence from the Initiation of Trade Reporting in Corporate Bonds. Journal of Financial Economics 82, 251-288.

Chen, L., D. Lesmond, and J. Wei (2007). Coporate Yield Spreads and Bond Liquidity. Journal of Finance 62, 119-149.

Chordia, T., R. Roll, and A. Subrahmanyam (2000). Commonality in Liquidity. Journal of Financial Economics 56, 3-28.

Colin-Dufresne, P., R. Goldstein, and J. S. Martin (2001). The Determinants of Credit Spread Changes. Journal of Finance 56, 2177-2207.

de Jong, F. and J. Driessen (2005). Liquidity Risk Premia in Corporate Bond Markets. Working Paper, University of Amsterdam.

Downing, C., S. Underwood, and Y. Xing (2005). Is Liquidity Risk Priced in the Corporate Bond Market? Working Paper, Rice University.

Edwards, A. K., L. E. Harris, and M. S. Piwowar (2007). Corporate bond market transaction costs and transparency. Journal of Finance 62, 1421-1451.

Fama, E. and J. MacBeth (1973). Risk, Return, and Equilibrium: Empirical Tests. Journal of Political Economy 81, 607-636.

Goldstein, M. A., E. S. Hotchkiss, and E. R. Sirri (2007). Transparency and Liquidity: A Controlled Experiment on Corporate Bonds. Review of Financial Studies 20, 235-273.

Grossman, S. and M. Miller (1988). Liquidity and Market Structure. Journal of Finance 38, 617-633.

Houweling, P., A. Mentink, and T. Vorst (2003). How to Measure Corporate Bond Liquidity? Working Paper, Erasmus University Rotterdam.

Huang, J. and M. Huang (2003). How Much of the Corporate-Treasury Yield Spread is Due to Credit Risk? Working Paper, Penn State and Cornell.

Huang, J. C. and J. Wang (2007). Liquidity and Market Crashes. Review of Financial Studies, forthcoming. 
Khang, K. and T.-H. D. King (2004). Return reversals in the bond market: evidence and causes. Journal of Banking and Finance 28, 569-593.

Longstaff, F., S. Mithal, and E. Neis (2005). Corporate Yield Spreads: Default Risk or Liquidity? New Evidence from the Credit-Default Swap Market. Journal of Finance 60, $2213-2253$.

Mahanti, S., A. Nashikkar, and M. Subrahmanyam (2008). Latent Liquidity and Corporate Bond Yield Spreads. Working Paper, New York University.

Nashikkar, A., S. Mahanti, M. Subrahmanyam, G. Chacko, and G. Mallik (2008). Latent Liquidity: A New Measure of Liquidity, with an Application to Corporate Bonds. Journal of Financial Economics 88, 272-298.

Newey, W. K. and K. D. West (1987). A Simple Positive Semi-Definite, Heteroskedasticity and Autocorrelation Consistent Covariance Matrix. Econometrica 29, 229-256.

Pastor, L. and R. F. Stambaugh (2003). Liquidity Risk and Expected Stock Returns. Journal of Political Economy 111, 642-685.

Roll, R. (1984). A Simple Implicit Measure of the Effective Bid-Ask Spread in an Efficient Market. Journal of Finance 39, 1127-1139.

Vayanos, D. and J. Wang (2008). A Unified Theory of Liquidity: A Synthesis. Working Paper, LSE and MIT. 